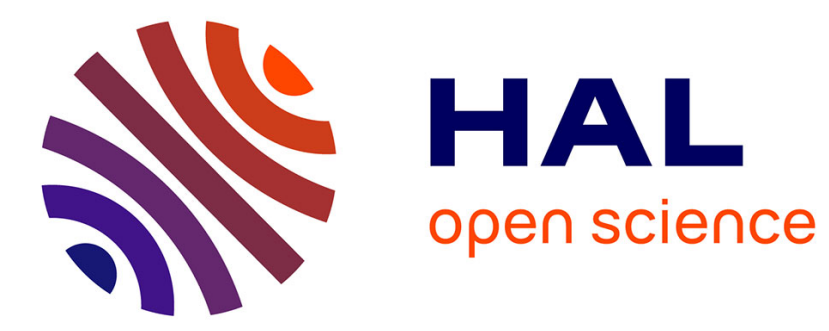

\title{
Surface tension, interfacial segregation and graphite shape in cast irons
}

\author{
J. Lacaze, O Dezellus
}

\section{To cite this version:}

J. Lacaze, O Dezellus. Surface tension, interfacial segregation and graphite shape in cast irons. Metallurgical and Materials Transactions B, In press, 10.1007/s11663-021-02352-x . hal-03437449

\section{HAL Id: hal-03437449 \\ https://hal.science/hal-03437449}

Submitted on 19 Nov 2021

HAL is a multi-disciplinary open access archive for the deposit and dissemination of scientific research documents, whether they are published or not. The documents may come from teaching and research institutions in France or abroad, or from public or private research centers.
L'archive ouverte pluridisciplinaire HAL, est destinée au dépôt et à la diffusion de documents scientifiques de niveau recherche, publiés ou non, émanant des établissements d'enseignement et de recherche français ou étrangers, des laboratoires publics ou privés. 
Surface tension, interfacial segregation and graphite shape in cast irons

J. Lacaze ${ }^{\mathrm{a}}$, O. Dezellus ${ }^{\mathrm{b}}$

a- CIRIMAT, Université de Toulouse, 4 allée Emile Monso, CS44362, 31030 Toulouse Cedex 4, France

b- LMI-UMR CNRS 5615 Université Lyon 1, 43 Bd du 11 novembre 1918, 69100 Villeurbanne, France

\begin{abstract}
Using literature data on iron melts, an expression of the surface tension of cast iron melts as a function of temperature and composition was obtained. Its predictions were satisfactorily compared with reported experimental results. Then, an analysis of experimental information of sessile drop experiments with cast iron melts onto graphite substrates showed a strong adhesion between these two phases when sulfur is present, and its dramatic decrease when the sulfur activity is reduced by the addition of spheroidizers such as $\mathrm{Mg}$ and Ce. Finally, analysis and discussion of results on the segregation of impurities and trace elements at the graphite matrix interface in cast irons led to the proposal of a scheme for their effect on graphite shape.
\end{abstract}

Keywords: cast iron, surface tension, interface segregation, microstructure, graphite shape

\title{
Corresponding authors:
}

JL: jacques.lacaze@ensiacet.fr

OD: olivier.dezellus@univ-lyon1.fr 


\section{Introduction}

Common spheroidal graphite cast irons are near-eutectic Fe-C-Si alloys which are prepared from rather pure pig iron, steel scraps and foundry returns. The charges thus contain some $\mathrm{O}$, $\mathrm{S}$, and $\mathrm{P}$, as well as some $\mathrm{Mn}$ at a minimum level of 0.10-0.15 wt.\%. The silicon content is set between 2.0 and $4.5 \mathrm{wt} . \%$ depending on the targeted final mechanical properties, and the carbon content is generally adjusted to be slightly higher than the liquid/austenite/graphite eutectic for minimizing shrinkage porosity during solidification. Controlling the microstructure of these alloys has two facets, on the one hand ensuring proper spheroidization of graphite and, on the other hand optimizing the as-cast matrix constitution, namely the amount of ferrite and pearlite.

Spheroidizing of graphite is achieved by addition of minute amounts of magnesium to the melt which leads to deoxidization and desulfurization. This effect may be reinforced by calcium and rare earths, but it is well established that a minimum of about $0.02 \mathrm{wt} \%$ of socalled free magnesium must be dissolved in the melt to ensure high nodularity graphite [1]. The latter result is a strong indication that magnesium directly affects graphite growth and it has long been proposed that this is by adsorption at the graphite/matrix interface. Attempts to evidence this adsorption has not always been successful and only a few works using electron microprobe have shown the presence of elemental $\mathrm{Mg}$ at the graphite/matrix interface [2-5].

High nodularity is however impeded by low cooling rate (heavy-section casting) and by the presence of low-level impurities amongst which the most known are antimony, bismuth, lead, tellurium, tin and titanium [6]. When present above a critical level of a few tens of ppm, these "anti-spheroidizing" elements lead to spheroidal graphite degenerating as spiky, crab-like and mesh graphite as recently reviewed [7]. Tellurium is known to strongly hinder graphite growth, and for this reason is used in thermal analysis before casting to check melt preparation [8]. Antimony is used to counter over-treatment with rare earth [9] but is also known to strongly promote pearlite [10], i.e., to hinder ferrite growth during the eutectoid transformation. For explaining these effects, it has been conjectured that tellurium and antimony accumulate at the graphite matrix interface forming a film hindering transfer of carbon to graphite nuclei or graphite precipitates. Such a film has been evidenced by Auger spectroscopy mapping $[10,11]$. Oxygen and sulfur have also been found to accumulate as a film at the graphite/matrix interface of lamellar graphite cast irons [12, 13] and are also known to increase the amount of pearlite. 
To rationalize the effect of these low level elements, it is usual to consider that they preferentially adsorb onto the outer surface of graphite precipitates and it is in this line that calculations based on density functional theory (DFT) have been performed [7, 14]. However, it is noticeable that $\mathrm{Bi}, \mathrm{O}, \mathrm{S}, \mathrm{Sb}, \mathrm{Sn}$ and Te are amongst the most surface active elements for iron melts, with As, $\mathrm{N}$ and Se. Following a proposal by Kozakevitch et al. [15] concerning sulfur, it would thus be of interest to consider the possibility that these elements segregate at the graphite/matrix interface as they do at the melt surface, and to discuss how they can affect graphite growth. The aim of this work is first to review thermodynamic data that allow expressing the surface tension of cast iron melts as function of composition. In a second part, experimental information on the graphite/melt interface will be reviewed and, finally, an attempt will be made to clarify the possible role of spheroidizing and "anti-spheroidizing" elements on graphite growth.

\section{Surface tension of cast iron}

\section{1 iron and some of its binary alloys}

For a long time, surface tension of high temperature melts was measured by either drop shape methods (sessile and pendant drop) or else the maximum bubble pressure technique, until apparition of levitation methods that rely on the analysis of oscillations frequencies of the melt free surface. Both techniques have been recently reviewed by Egry et al. [16]. As no relevant surface tension measurements of cast iron by levitation methods has been found in the existing literature data, emphasis is put on drop shape methods. Amongst this series of techniques, the sessile drop is certainly the most widely used and accurate provided that the melt chemistry is rigorously controlled (especially for surface active elements), the melt density is precisely known, the drop shape is well-defined and axisymmetric, the contact angle on solid surface is much higher than $90^{\circ}$, the roughness of the solid is low and controlled, and a perfectly aligned optical line with a magnification factor higher than 1 is used to perform acquisition of the drop meridional profile. If these conditions are achieved, the values of surface tension are determined to better than $2 \%[15,17]$. For this technique as others, great care must be taken in avoiding contamination of the melt and evaporation in case of alloys, and this requires chemical analysis of the samples before and after experiments. In 
the present work, use will be made of the assessment by Mills and Su [18] expressing the temperature dependence of the surface tension of pure liquid iron, $\sigma_{\mathrm{Fe}}^{\mathrm{L} / \mathrm{V}}$, as:

$$
\sigma_{\mathrm{Fe}}^{\mathrm{L} / \mathrm{V}}=1880-0.41 \cdot\left(\mathrm{T}_{\mathrm{K}}-1811\right)\left[\mathrm{mN} \cdot \mathrm{m}^{-1}\right]
$$

where $T_{K}$ is the temperature in Kelvin.

The density of pure liquid iron selected by Yoshikawa [19] is:

$\rho_{\mathrm{Fe}}=7.035-0.926 \cdot 10^{-3} \cdot\left(\mathrm{T}_{\mathrm{K}}-1811\right)\left[\mathrm{g} \cdot \mathrm{cm}^{-3}\right]$

Keene [20] has made an exhaustive review of surface tension of iron and its binary alloys which relies much on the pioneering work by Kozakevitch and Urbain [17, 21, 22]. In this latter work, the sessile drop technique was used with all precautions to avoid contamination, or to control it, performing chemical analysis before and after experiments and evaluating the density of every alloy. Furthermore, Kozakevitch et al. [15, 17, 21, 22] checked for any asymmetry of the drop by performing measurements after 4 rotations of $90^{\circ}$ of the drop. Fig. 1 shows the effect of several elements at $1550^{\circ} \mathrm{C}$ where the reference surface tension is 1788 $\mathrm{mN} \cdot \mathrm{m}^{-1}$ for an iron without sulfur and with less than $10 \mathrm{ppm}$ per mass of oxygen. It should be noticed that this value is more than $5 \%$ lower than the reference surface tension recommended by Mills and Su (eq. 1) and this may be attributed to the presence of oxygen. However, whatever the existence of a systematic bias on the absolute value of the reference surface tension because of contamination, the main interest of the data by Kozakevitch and Urbain relies on the systematic study of the effect of alloying additions. Se, O, S and N appear highly surface active, $\mathrm{Sb}$ and $\mathrm{Sn}$ are strongly surface active, while $\mathrm{P}, \mathrm{Si}$ and $\mathrm{C}$ are not. As Keene noted, the results for C, N, S, and O in Fig. 1 are in fairly good agreement with other results, both recent - at the time of Keene's review - and not so recent as those often referenced by Halden and Kingery [23]. 


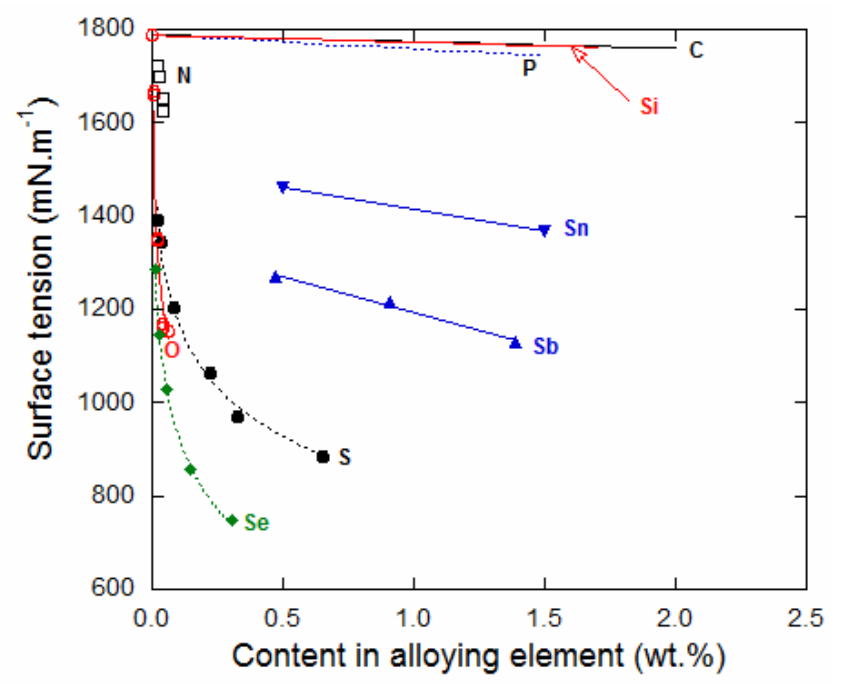

Figure 1. Effect of some elements on the surface tension of liquid iron at $1550^{\circ} \mathrm{C}$. Data from Kozakevitch and Urbain [21, 22].

Table I shows for a few elements $i$ the surface activity that is defined as its effect on the surface tension at infinite dilution, $d \sigma /\left.d x_{i}\right|_{x_{i} \rightarrow 0}$, where $x_{i}$ is the mole fraction of $i$. Results from Kozakevitch and Urbain at $1550^{\circ} \mathrm{C}$ may thus be compared with the values assessed by Keene for data between $1550^{\circ} \mathrm{C}$ and $1600^{\circ} \mathrm{C}$. Amongst the data available to Keene, those by Nogi and Ogino [24] on the most surface active elements, O, S, Se and Te, are quite close to those of Kozakevitch and Urbain. Also, it should be noted that Kozakevitch and Urbain considered that metals, including rare earths, have a very small effect on the surface tension of iron while contrasted results have been reported by Keene.

For elements of group VI that strongly adsorb on liquid iron, the Langmuir isotherm that relies on a monolayer of atoms or molecules at the surface has been found appropriate [25] though having some theoretical drawbacks for not dilute solutions [26]. One can thus express the surface tension of a Fe-i binary alloy at given temperature $T_{K}$ as:

$$
\sigma^{\mathrm{L} / \mathrm{V}}=\sigma_{\mathrm{Fe}}^{\mathrm{L} / \mathrm{V}}-\mathrm{R} \cdot \mathrm{T}_{\mathrm{K}} \cdot \Gamma_{\mathrm{i}}^{\mathrm{sat}} \cdot \ln \left(1+\mathrm{K}_{\mathrm{ads}}\left(\mathrm{T}_{\mathrm{K}}\right) \cdot \mathrm{a}_{\mathrm{i}}\right)
$$

where $\mathrm{R}$ is the gas constant, $\Gamma_{\mathrm{i}}^{\text {sat }}$ is the adsorption at full coverage (saturation of the surface monolayer), $K_{a d s}\left(T_{K}\right)$ is the equilibrium constant of the adsorption reaction and $a_{i}$ is the 
activity of element $i$ in the melt. $\mathrm{K}_{\mathrm{ads}}\left(\mathrm{T}_{\mathrm{K}}\right)$ may be conveniently represented by the following expression [27]:

$$
\mathrm{K}_{\mathrm{ads}}\left(\mathrm{T}_{\mathrm{K}}\right)=\exp \left(-\frac{\Delta \mathrm{S}_{\mathrm{ads}}}{\mathrm{R}}\right) \cdot \exp \left(-\frac{\Delta \mathrm{H}_{\mathrm{ads}}}{\mathrm{R} \cdot \mathrm{T}_{\mathrm{K}}}\right)=\mathrm{k}_{\mathrm{ads}} \cdot \exp \left(-\frac{\Delta \mathrm{H}_{\mathrm{ads}}}{\mathrm{R} \cdot \mathrm{T}_{\mathrm{K}}}\right)
$$

where $\Delta \mathrm{S}_{\mathrm{ads}}$ and $\Delta \mathrm{H}_{\mathrm{ads}}$ are the entropy and the enthalpy of the adsorption reaction, respectively. These latter quantities are generally assumed not to depend on temperature so that $\mathrm{k}_{\mathrm{ads}}$ is a constant whose value depends however on the choice of the activity scale. The adsorption enthalpy may be determined from adsorption isotherm at different temperatures and the $\mathrm{k}_{\mathrm{ads}}$ constant by fitting to the linear part of such isotherms [25]. Details about experimental data and their quantitative description are given in appendix I for oxygen, appendix II for carbon and appendix III for sulfur and C-S interactions.

Table I. Effect on the liquid iron surface tension of dilute addition of various elements, $-\mathrm{d} \sigma /\left.\mathrm{dx}_{\mathrm{i}}\right|_{\mathrm{x}_{\mathrm{i}} \rightarrow 0}$, expressed in $\mathrm{mN} \cdot \mathrm{m}^{-1} \cdot(\text { at. } \%)^{-1}$ and the approximate range of validity (at.\%).

\begin{tabular}{|l|l|l|l|l|}
\hline Group & Element & $-\mathrm{d} \sigma / \mathrm{dx}_{\mathrm{i}}[22]$ & $-\mathrm{d} \sigma / \mathrm{dx}_{\mathrm{i}}[20]$ & range \\
\hline \multirow{4}{*}{ III } & $\mathrm{Al}$ & 38 & 18 & $0-10$ \\
\cline { 2 - 5 } & $\mathrm{B}$ & 26 & 25 & $0-10$ \\
\hline \multirow{5}{*}{ V } & $\mathrm{C}$ & 3 & 4 & $0-10$ \\
\cline { 2 - 5 } & $\mathrm{Si}$ & $4-7.5$ & 13 & $0-5$ \\
\cline { 2 - 5 } & $\mathrm{Sn}$ & 1655 & 1630 & $0-0.15$ \\
\hline \multirow{5}{*}{$\mathrm{V}$} & $\mathrm{N}$ & 850 & 1400 & $0-0.1$ \\
\cline { 2 - 5 } & $\mathrm{P}$ & $10-16$ & 14 & $0-1$ \\
\cline { 2 - 5 } & $\mathrm{Sb}$ & 3900 & 2200 & $0-0.1$ \\
\hline \multirow{3}{*}{ VI } & $\mathrm{O}$ & 8600 & 7490 & $0-0.03$ \\
\cline { 2 - 5 } & $\mathrm{S}$ & 15400 & 6310 & $0-0.05$ \\
\cline { 2 - 5 } & $\mathrm{Se}$ & 54600 & 35000 & $0-0.01$ \\
\cline { 2 - 5 } & $\mathrm{Te}$ & $>54600$ & 190000 & $0-0.0025$ \\
\hline
\end{tabular}

One important feature associated with strongly surface active elements is that they can easily change the temperature slope of the surface tension. This was illustrated in the case of oxygen by Morohoshi et al. [28] and is shown again in Fig. 2 using eq. (A3) in Appendix I. It is thus seen that the slope changes from positive to negative at about $1900 \mathrm{~K}$ for an oxygen activity of $10^{-6}$. It should be noted, however, that each curve in Fig. 2 was calculated for a constant 
oxygen activity when in fact it decreases with temperature for a given oxygen content in the melt.

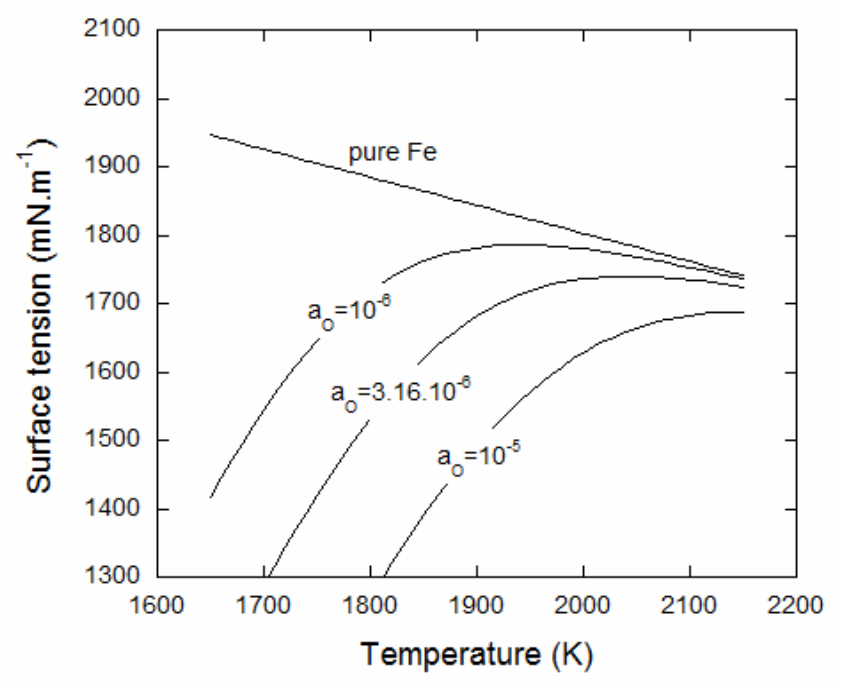

Figure 2. Effect of temperature and oxygen activity on the surface tension of iron. Oxygen activity is referenced to pure oxygen gas at $1 \mathrm{~atm}$. and the current temperature. The line labelled "pure Fe" was drawn according to Eq. 1.

In industrial alloys, co-segregation of various elements may have to be considered and it has been claimed this is the case of $\mathrm{O}$ and $\mathrm{S}$ at the surface of liquid steel [29, 30]. Hajra and Divakar [31] developed a model that accounts for specific interactions between elements segregated at the surface and applied it to the Fe-S-O system at high temperature (1873 K and 1923 K). Based on results by Keene et al. [32], they found a very small surface interaction coefficient between $\mathrm{O}$ and $\mathrm{S}$, which however would be sufficient to give an advantage to $\mathrm{S}$ over $\mathrm{O}$ during an increase in temperature. This appears in contrast with the conclusion of Keene et al. who considered that most of their results showed a linear relation, i.e. a simple additive rule and no competition between these elements. This discrepancy certainly comes from the fact that Hajra and Divakar focused on high $\mathrm{O}$ and $\mathrm{S}$ contents. For the present study that deals with cast irons, the presence of silicon will ensure that there is little oxygen in the melt and thus little segregated at the surface. Similarly, $\mathrm{S}$ is expected to repel $\mathrm{C}$ from the surface $[15,26]$ and the fact that carbon increases the activity of sulfur in the melt must be accounted for. Provided this is done, one may certainly use a simple additive rule to express the effect of several impurities for Fe-C-Si alloys and cast irons as already used by Chung and Cramb [30] for liquid steel. This is detailed in the next sub-section. 


\subsection{Fe-C-Si alloys and cast irons.}

For elements that do not strongly segregate as is the case of carbon, silicon and phosphorus, the above formalism making use of the Langmuir isotherm (eq. 3) does not appear suitable because insufficient data is available. Accordingly, simple linear relations were looked for and it appeared impossible to find enough results to check if such relations are reasonably temperature independent. The effect of carbon on the surface tension of iron in Fe-C melts is discussed in Appendix II where it is finally suggested to consider that it has little or no effect at amounts less than $5 \mathrm{wt} . \%$ that are relevant for cast irons.

Kozakevitch and Urbain [22] proposed a linear relation between the surface tension in $\mathrm{Fe}-\mathrm{Si}$ alloys and the silicon content at $1550^{\circ} \mathrm{C}$, and estimated a slope of $-15 \mathrm{mN} \cdot \mathrm{m}^{-1} \cdot(\mathrm{wt} . \% \mathrm{Si})^{-1}$ which is in accordance with the results reviewed by Yoshikawa [19]. It should also be noted that the very extensive series of experiments by Kawai et al. [33] appeared inconsistent and could not be used, probably because the level of purity of the iron $(99.5 \% \mathrm{Fe})$ was not high enough.

Based on results at $1450^{\circ} \mathrm{C}$ by Whalen et al. [34] on Fe-3wt.\%C-Si alloys with silicon content up to $5.10 \mathrm{wt} . \%$, it has been suggested that there could be some associative effect of $\mathrm{C}$ and $\mathrm{Si}$ at the surface $[26,35]$ with the formation of Si-C associates. This has not been confirmed by the more recent results by Yoshikawa [19] who did not find an effect of carbon at high silicon contents (30-40 at.\%) where it would be mostly expected. Moreover, if this effect were to exist in Fe-C-Si alloys, it would not show up in cast irons because sulfur repels carbon from the surface. The results by Whalen et al. are plotted in Fig. 3 together with some other data. For silicon content lower than $5 \mathrm{wt}$.\% which is the range for cast irons, it is seen that the results can be fitted with a line writing $\left(1915-46.1 \cdot \mathrm{w}_{\mathrm{Si}}\right) \mathrm{mN} \cdot \mathrm{m}^{-1}$, where $\mathrm{w}_{\mathrm{Si}}$ is the wt.\% content of Si. It is worth noting that the value at $0 \mathrm{wt} . \% \mathrm{Si}$ is nearly the same as that for pure $\mathrm{Fe}$ at $1450^{\circ} \mathrm{C}$ (eq. 1), thus supporting the lack of effect of carbon. For completeness, it should be mentioned that the value reported by Whalen et al. for a Fe-3\% $\mathrm{C}$ alloy is slightly higher at $1950 \mathrm{mN} \cdot \mathrm{m}^{-1}$. As mentioned above, the iron used by Kozakevitch and Urbain [22] had a surface tension of $1788 \mathrm{mN} \cdot \mathrm{m}^{-1}$ which explains their measure is located below those of Whalen et al. in Fig. 3. The result at about 18 wt.\% Si from Yoshikawa has been reported to 
illustrate the expected saturation effect. Though the slope which is obtained in Fig. 3 is larger than those listed in Table I, even after conversion to at.\%, it will be accepted in the following.

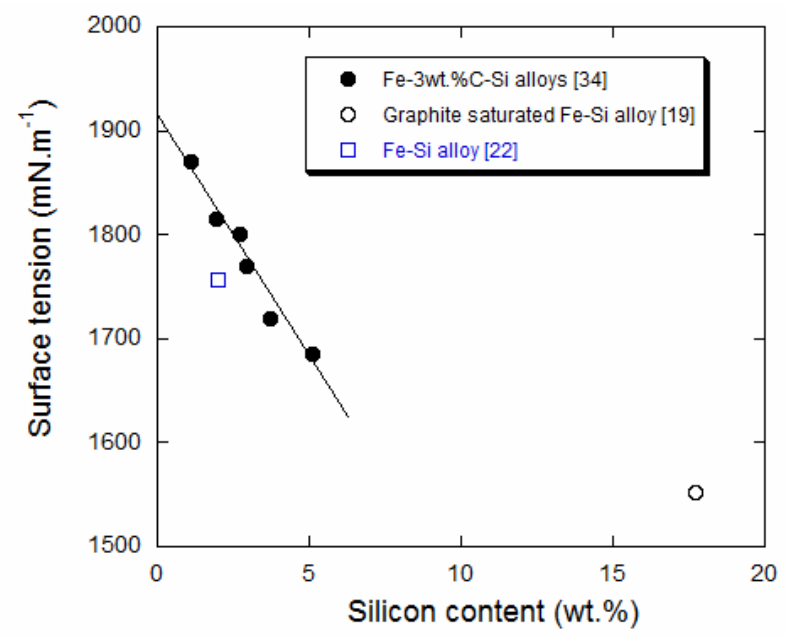

Figure 3. Effect of silicon on the surface tension of iron and $\mathrm{Fe}-\mathrm{C}$ alloys at $1450^{\circ} \mathrm{C}$. Data from Whalen et al. [34], Yoshikawa [19] and Kozakevitch and Urbain [22].

Of the surface tension measurements of cast iron, the most difficult are certainly those intended to study the effect of magnesium. Vashchenko and Rudoi [36] performed experiments using the maximum bubble pressure technique with batches of $0.5 \mathrm{~kg}$ of metal. For Mg treated alloys (typical composition given as 3.60 C, $1.80 \mathrm{Si}, 0.50 \mathrm{Mn}, 0.035 \mathrm{P}, 0.011$ $\mathrm{S}$, wt.\%) which were melted at $1390^{\circ} \mathrm{C}$, the $\mathrm{Mg}$ content decreased from 0.032 to $0.012 \mathrm{wt} . \%$ during the experiment, while the surface tension first increased and passed through a maximum at about $0.017 \mathrm{wt} \% \mathrm{Mg}$, see Fig. 4. It may be expected that this value represents the amount of dissolved magnesium as any $\mathrm{MgS}$ or $\mathrm{MgO}$ compounds have certainly floated at the surface of the melt. The authors considered that this increase was characteristic of a surface active element and estimated the effect of $\mathrm{Mg}$ as $8000 \mathrm{mN} \cdot \mathrm{m}^{-1} \cdot(\mathrm{wt} . \%)^{-1}$. This value is very high when compared to other elements (see Table I) and seems dubious as it should be associated with marked interface segregation of $\mathrm{Mg}$ which has never been reported, see later in this paper. The other work worth of mention is that of Selçuk and Kirkwood [37] using the sessile drop technique. They followed the surface tension of a spheroidized alloy (3.58 C, 2.60 Si, $0.14 \mathrm{Mn}, 0.022 \mathrm{P}, 0.012 \mathrm{~S}$, wt.\%) during a 60 minute holding at $1180^{\circ} \mathrm{C}$. The amount of magnesium varied from $0.038 \mathrm{wt} . \%$ to $0.008 \mathrm{wt} . \%$ within this time interval while the surface tension decreased from $1350-1490 \mathrm{mN} \cdot \mathrm{m}^{-1}$ to $1150-1190 \mathrm{mN} \cdot \mathrm{m}^{-1}$. The authors 
associated this decrease to fading of $\mathrm{Mg}$ and thus to release of sulfur in the melt as they did not find any loss of total sulfur. Fig. 4 shows the results of these two studies and suggests that the increase observed by Vaschenko and Rudoi was related to Mg catching up progressively $\mathrm{S}$ and $\mathrm{O}$ until it started to fade.

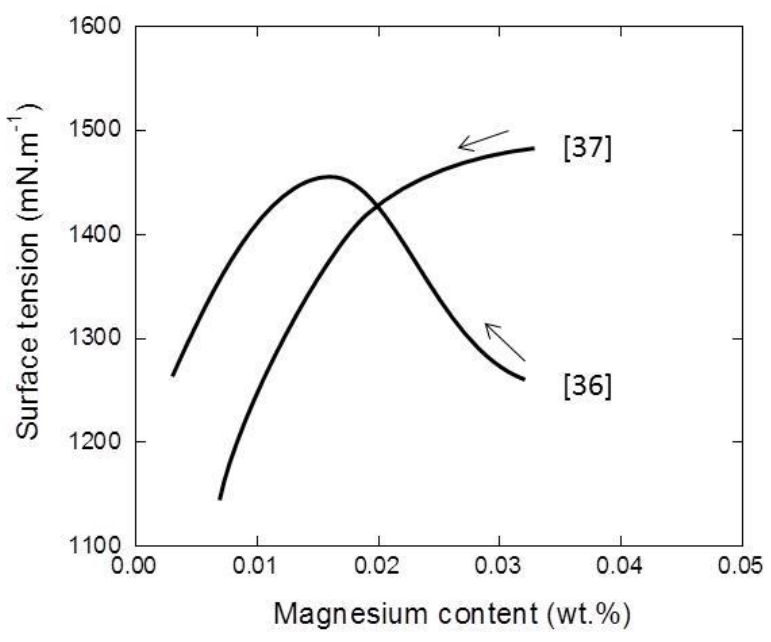

Figure 4. Effect of Mg on the surface tension of cast iron. Experimental results of Selçuk and Kirkwood [37] at $1180^{\circ} \mathrm{C}$ with the sessile drop technique and Vashchenko and Rudoi [36] at $1390^{\circ} \mathrm{C}$ with the maximum bubble pressure technique. The arrows indicate the change recorded during the experiments.

As seen Table I, data are also available for $\mathrm{P}, \mathrm{Sb}$ and $\mathrm{Sn}$ for which the values proposed by Kozakevitch and Urbain [22] will be considered. According to the above and to eq. (A3) in Appendix I and eq. (A6) in Appendix III, the surface tension of a cast iron would be given by the following equation:

$$
\begin{aligned}
\sigma^{\mathrm{L} / \mathrm{V}}= & 1880-0.41 \cdot\left(\mathrm{T}_{\mathrm{K}}-1811\right)-0.153 \cdot \mathrm{T}_{\mathrm{K}} \cdot \ln \left(1+4 \cdot 10^{-5} \cdot \exp \left(\frac{355000}{\mathrm{R} \cdot \mathrm{T}_{\mathrm{K}}}\right) \cdot \mathrm{a}_{\mathrm{O}}\right) \\
& -0.107 \cdot \mathrm{T}_{\mathrm{K}} \cdot \ln \left(1+0.03 \cdot \exp \left(\frac{232000}{\mathrm{R} \cdot \mathrm{T}_{\mathrm{K}}}\right) \cdot \mathrm{a}_{\mathrm{S}}\right) \\
& -46.1 \cdot \mathrm{w}_{\mathrm{Si}}-30 \cdot \mathrm{w}_{\mathrm{P}}-1690 \cdot \mathrm{w}_{\mathrm{Sb}}-560 \cdot \mathrm{w}_{\mathrm{Sn}}
\end{aligned}
$$

where $\mathrm{w}_{\mathrm{i}}$ is the wt.\% content in element $\mathrm{i}$.

As seen with Fig. 2 and eq. 5, the effect of oxygen is expected to be significant on iron melts. As a matter of fact, however, the oxygen content of cast irons is generally not reported 
because being very low. Furthermore, this is the amount of dissolved oxygen that is important for surface tension which is very rarely measured apart for the extensive work carried out by Mampaey et al. [38]. According to these authors, the oxygen content in a melt for lamellar iron is about $1 \mathrm{ppm}$ at $1420^{\circ} \mathrm{C}$, and decreases to about $0.1 \mathrm{ppm}$ after magnesium treatment. With the oxygen content at $35 \mathrm{ppm}$ indicated by Mil'man et al [39] for flake graphite in Appendix IV, precipitation of silicon oxides is predicted using the TCFE-11 database [40] and the activity of oxygen falls at $3 \cdot 10^{-9}$ at $1300^{\circ} \mathrm{C}$. At equilibrium, the effect of oxygen on the surface tension of cast irons is thus expected to be negligible. However, kinetics of dissolution or precipitation of oxygen-bearing compounds may lead to transients during which the freeoxygen content is higher than predicted by equilibrium [38].

Eq. 5 suggests that sulfur should exhibit the same temperature effect as observed for oxygen in Fig. 2. This was indeed shown experimentally by Vashchenko et al. [41] who used the maximum bubble technique. These authors measured the surface tension of three irons with 0.03 wt. $\% \mathrm{~S}$ and different carbon equivalent between $1250^{\circ} \mathrm{C}$ and $1780^{\circ} \mathrm{C}$ and found an evolution showing a maximum at about $1500^{\circ} \mathrm{C}$. However, the values reported at this maximum were very low at about $1200 \mathrm{mN} \cdot \mathrm{m}^{-1}$ suggesting that strongly surface active impurities other than sulfur were also present in their alloys. As a matter of fact, it did not appear feasible to reconcile these results with those discussed in appendix III.

In the appendix IV are listed and shortly described a number of surface tension values of cast irons reported in the literature, including alloys having been spheroidized and not. These results are plotted in Fig. 5-a as function of the sulfur content, differentiating spheroidized alloys represented with open symbols from not-spheroidized ones represented with solid symbols. The data appears scattered, which may be because of the differences in the experimental temperatures and perhaps also because they were obtained using various techniques. Many experimental drawbacks can be encountered leading to a significant increase of measurement errors up to $10 \%$ (see [42] for a review of good practice). However, despite these limitations, the effect of sulfur is evidenced and Kozakevitch et al. [15] decreased the scatter by replotting their data versus sulfur activity instead of sulfur content. The same has been done in figure 5-b using a logarithmic axis as is usual in studies on interface tension. The first relevant observation is that almost all the data for spheroidised alloys (low sulfur activity) are scattered from 1100 to $1900 \mathrm{mN} \cdot \mathrm{m}^{-1}$. However, scattering would be lowered by the removal of the datasets from Takida et al. [44] and McSwain [43] that are characterized by less reliable measurement and that suffer from inconsistency (see 
section 3.1). The second observation is the linear dependency of surface tension with sulfur activity for non-spheroidized alloys (high sulfur activity) that is in good agreement with a Gibbsian adsorption phenomenon of sulfur at the liquid/vapor interface.
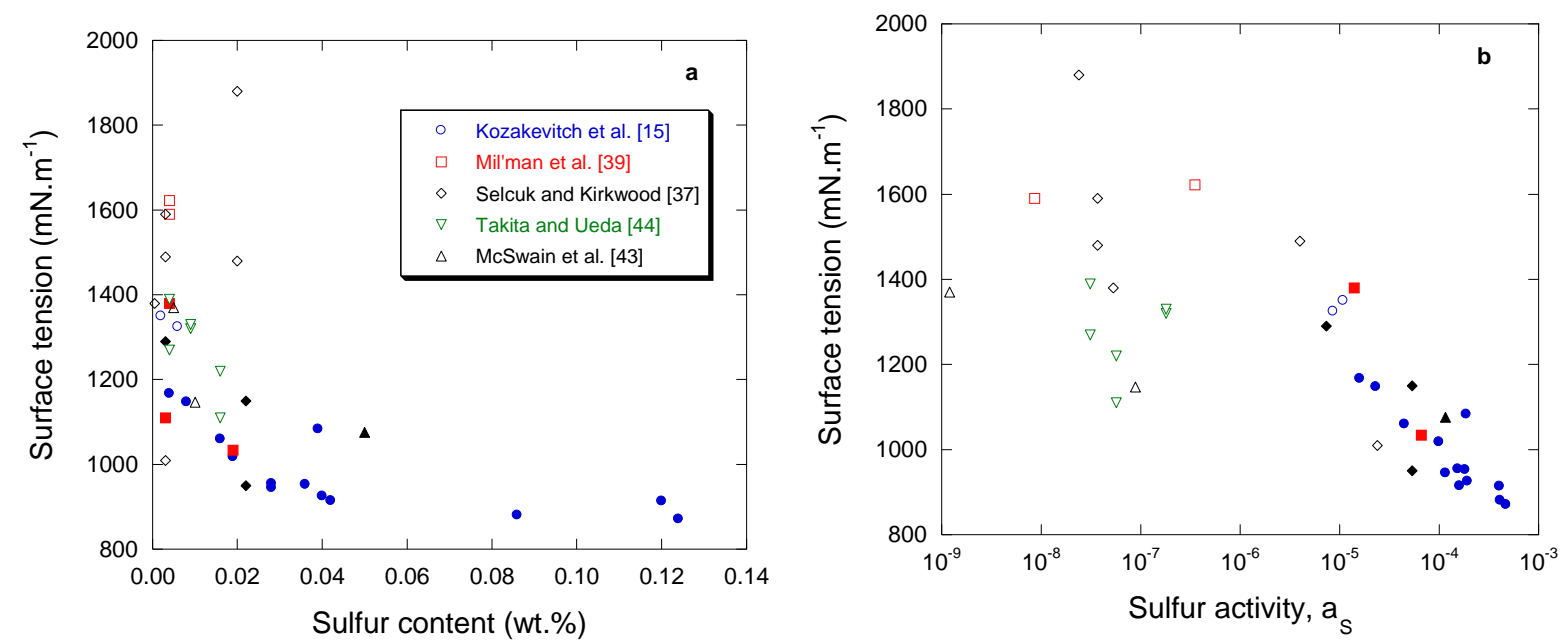

Figure 5. Comparison of surface tension of various cast irons plotted versus sulfur content (a) and versus sulfur activity (b) for spheroidized (open symbols) and not spheroidized alloys (solid symbols). Sulfur activity was calculated with the TCFE-11 database with reference to pure gaseous sulfur at 1 atm. and current temperature. The same symbols are used in a and b to plot the data from Kozakevitch et al. [15], Mil'man et al. [39], Selçuk and Kirkwood [37], Takita and Ueda [44] and McSwain et al. [43].

Fig. 6 shows the experimental surface tension versus the one calculated with eq. 5 . The results which are reported are those for which the calculated sulfur activity is given in Appendix IV. The main effects of sulfur activity and temperature appear properly accounted for and the agreement between prediction and measurements is quite good for surface tension up to 1400 $\mathrm{mN} \cdot \mathrm{m}^{-1}$, i.e. mostly data for untreated melts. However, the agreement may still be considered as satisfactory for higher surface tension values if the results which are circled, i.e. those by McSwain and Bates [43] and Takita and Ueda [44], are excluded. It will be seen in section 3.1 that a low weight can effectively be put on these results. Thus, if temperature and sulfur effects are properly described by eq. 5 , then the overestimation for spheroidized melts appearing in Fig. 6 suggests that the actual content of spheroidizer in the melt was lower than expected when the surface tension measurements were carried out. In other words, the sulfur activity may be much higher than calculated assuming equilibrium as was done. 


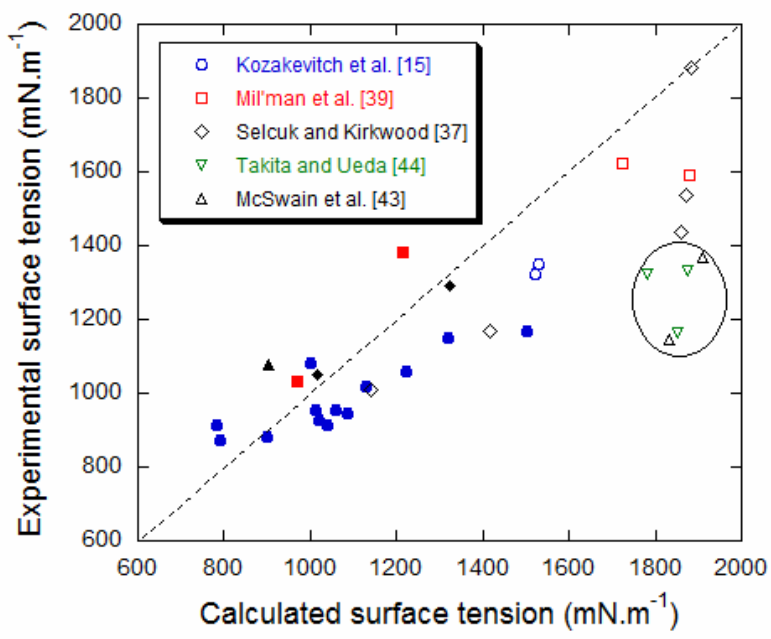

Figure 6. Experimental versus predicted surface tension of cast iron melts. Solid and open symbols are for untreated and spheroidized melts, respectively. The dashed line is the bisector. Data from Kozakevitch et al. [15], Mil'man et al. [39], Selçuk and Kirkwood [37], Takita and Ueda [44] and McSwain et al. [43].

\section{Interfacial segregation and graphite shape}

Precipitation of graphite from a liquid cast iron is associated to the formation of a graphite/liquid interface whose properties are expected to affect the shape of the evolving graphite precipitates. Results on the wetting characteristics of cast iron melts on graphite are first described, followed by a review of available results about segregation at the graphite/liquid interface and then by a discussion of the possible consequences on the evolving graphite shape.

\subsection{Adhesion work of the graphite/melt interface in cast irons}

In many of the studies using the sessile drop technique with cast iron melts, the substrate was graphite for evaluating at the same time the properties of the graphite/liquid interface. Review of experimental information on ferrous metals, $\mathrm{Fe}$, $\mathrm{Co}$ and $\mathrm{Ni}$, suggests that metal presaturated in carbon does not wet graphite while apparent contact angle lower than $90^{\circ}$ could be observed for pure metal. However, this apparent wetting is meaningless because it is induced by a significant dissolution of the substrate leading to a modification of the interface 
which is no longer flat [45]. On the contrary, for carbon saturated Fe-C-Si alloys or cast irons, it is expected there will be no dissolution reaction taking place at the graphite/liquid interface and, in that case, the following Young's equation applies:

$\sigma^{\mathrm{L} / \mathrm{V}} \cdot \cos \theta=\sigma^{\mathrm{Gra} / \mathrm{V}}-\sigma^{\mathrm{Gra} / \mathrm{L}}$

where $\sigma^{\mathrm{Gra} / \mathrm{L}}$ and $\sigma^{\mathrm{Gra} / \mathrm{V}}$ are the interface tension between graphite and liquid and the surface energy of graphite, respectively, and $\theta$ is the contact angle at the triple line.

When available, detailed data for contact angle have been given in Appendix IV alongside surface tension values. As is the case for the surface tension measurements, it has to be emphasized that contact angle measurement, despite its apparent simplicity, remains a major problem with poor repeatability when the experiments are not carefully prepared [46]. Beyond the experimental sources for measurement errors such as substrate preparation and purity of the materials and atmosphere, several measurement technics could be used and each one requires specific conditions. Dissolution can readily happen in case the alloy has not been properly saturated in carbon [45] or when the temperature during wetting experiment is increased above that used for saturation [47]. Furthermore, high roughness of the substrate may also favor pinning of the triple line and therefore hinder reaching the equilibrium contact angle [48]. Both cases lead to major errors on the contact angle when measured on the projected image of the drop on the substrate. Also, amongst the studies selected and detailed in Appendix IV, only Mil'man et al. directly measured the contact angle using the tangent method. All the other values are issued from a liquid/vapour surface tension measurement and an extension of the drop profile down to the graphite substrate.

Selçuk and Kirkwood [37] used apparently polycrystalline graphite which was polished to produce a smooth surface that they expected to be predominantly of (0001) basal character. The values they reported for S-, Mg- and Ce-bearing alloys at the beginning and end of experiments conducted at about $1200^{\circ} \mathrm{C}$ have been selected. McSwain and Bates [43] made measurements on both polycrystalline graphite and pyrolytic graphite, this latter being oriented so that the melt was in contact with either the basal or prism planes. Their results for basal and prism planes at $1200^{\circ} \mathrm{C}$ for S-, $\mathrm{Mg}$ - and Ce-bearing melts were considered. Mil'man et al. [39] carried out the same type of experiments at $1300^{\circ} \mathrm{C}$ on a large number of alloys amongst which two untreated melts with very different $S$ content $(0.004$ and 0.019 wt.\%) as well as one Mg-and one Ce-bearing alloy. Finally, the results of Takita and Ueda [44] for 
their Mg-bearing alloy at $1180^{\circ} \mathrm{C}$ on both pyrolytic (basal oriented) and polycrystalline graphite were also selected.

Fig. 7 shows the plot of the contact angle results of these four studies and a large scatter between the different authors may be noticed. However, within each series of results, there is a clear trend of a higher contact angle for spheroidized melts than for untreated melts. It is however quite striking that a value lower than $90^{\circ}$ was reported by McSwain and Bates [43], and in fact the contact angle values reported by these authors are systematically the lowest ones and can even be typical of a situation where graphite is wetted by the iron melt. As a matter of fact, these authors used samples $12 \mathrm{~mm}$ in diameter and $7 \mathrm{~mm}$ in height, meaning that the drop equilibrated with a receding triple line, i.e., in conditions highly sensitive to pining. This may have affected the values of both the contact angles and of the surface tension. Though Takita and Ueda do not give all experimental details, their contact angle values for $\mathrm{Mg}$ treated alloys are also very low, leading as well to very low surface tension values. This is why low weight should be put on the surface tension values from these two works as noticed in relation with Fig. 6.

According to the Young's equation (eq. 6), a decrease of the surface tension in the case of a non-wetting system should lead to an increase of the contact angle if the two other interface energies, namely $\sigma^{\mathrm{Gra} / \mathrm{V}}$ and $\sigma^{\mathrm{Gra} / \mathrm{L}}$, remain constant. However, Fig. 7 gives evidence of the reverse situation: the contact angles observed for high sulfur activity alloys ( $\mathrm{S}$ and low $\mathrm{S}$ bearing) being lower than the one of low sulfur activity alloys (Mg or Ce bearing). As a consequence, one or both of these two interfacial energies should also evolve with increase in sulfur activity leading to a decrease of the contact angle.

Unfortunately, the surface tension of graphite at the temperature of interest is quite badly known. Selçuk and Kirkwood [37] evaluated $\sigma^{\mathrm{Gra} / \mathrm{V}}$ for basal and prism planes from the associated Young's modulus and distance between carbon atoms and found values of the order of $\sigma^{\mathrm{Gra}-\text { basal } / \mathrm{V}}=290$ and $\sigma^{\mathrm{Gra}-\mathrm{prism} / \mathrm{V}}=4300$, respectively $\left(\mathrm{mN} \cdot \mathrm{m}^{-1}\right)$. The significant differences between the two types of crystallographic planes are due to the high anisotropy of the graphite structure and of the related Young's modulus. Roviglione and Hermida [49] reported values from Kelly at 234 and $1250 \mathrm{mN} . \mathrm{m}^{-1}$ for basal and prism planes, respectively, which are consistent with the above estimates. On the contrary, the often used evaluations by Rhee [50] give a value of about $1000-1100 \mathrm{mN} \cdot \mathrm{m}^{-1}$ for both prism and basal planes at 
$1200^{\circ} \mathrm{C}$. This appears doubtful and may be due to the fact that Rhee analyzed data at very high temperature and proposed relations that are then extrapolated far from their validity range.

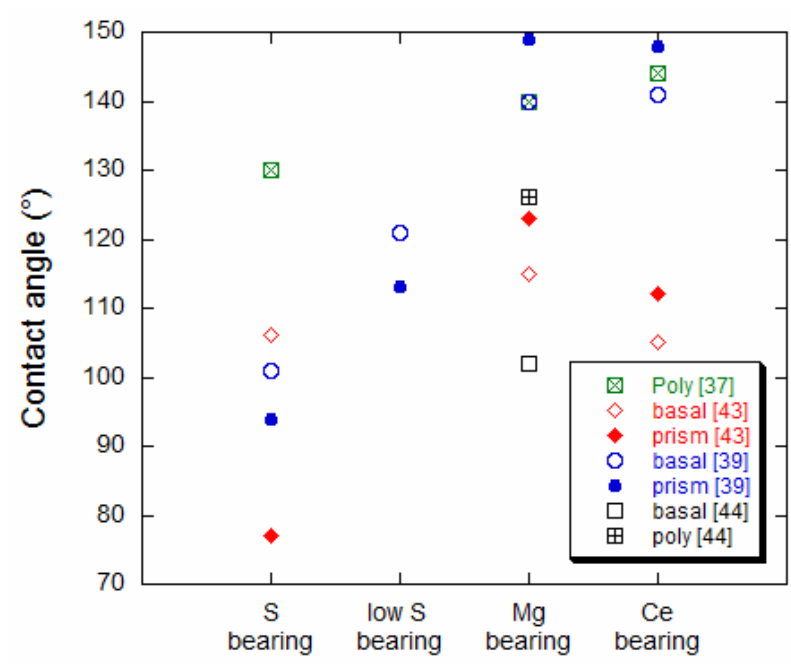

Figure 7. Values of the contact angle between graphite and carbon-saturated melts. Solid (resp. open) symbols are for experiments on prism (resp. basal) planes of graphite, and "poly" stands for polycrystalline graphite. Data from Mil'man et al. [39], Selçuk and Kirkwood [37], Takita and Ueda [44], and McSwain et al. [43].

It is not generally considered that the alloying elements present in the drop of cast iron can affect $\sigma^{\mathrm{Gra} / \mathrm{V}}$. However, this possibility was considered by Jung et al. [47] and they carried out experiments with an intentional partial dissolution of the graphite substrate. Accordingly, the Young's equation should be replaced by Neuman's relation and the three contact angles at the tripe line should be measured and then used together with $\sigma^{\mathrm{L} / \mathrm{V}}$ to get the other two interface tensions. The authors concluded that sulfur at level higher than $11 \mathrm{ppm}$ does adsorb on the free surface of graphite and thus affects $\sigma^{\mathrm{Gra} / \mathrm{V}}$, but their measurements are not detailed and they used values from the literature for the surface tension rather than measuring it. Such experiments should be carried out again but, at present time, there is too much uncertainty on the value of the graphite surface tension to use it together with Young's equation for evaluating $\sigma^{\mathrm{Gra} / \mathrm{L}}$.

We are thus left with only the contact angle and the surface tension to investigate the evolution of the graphite/liquid interface without making any hypothesis on the value of 
$\sigma^{\mathrm{Gra} / \mathrm{V}}$. The right hand side of eq. 6 is the opposite of the work of immersion $\left(\mathrm{W}_{\mathrm{i}}\right)$ that was also called relative interface energy by Selçuk and Kirkwood [37]:

$\mathrm{W}_{\mathrm{i}}=-\sigma^{\mathrm{L} / \mathrm{V}} \cdot \cos \theta=\sigma^{\mathrm{Gra} / \mathrm{L}}-\sigma^{\mathrm{Gra} / \mathrm{V}}$

Another way of characterizing the graphite/melt interface is using the so-called work of adhesion, $\mathrm{W}_{\mathrm{a}}$, defined as:

$\mathrm{W}_{\mathrm{a}}=\sigma^{\mathrm{L} / \mathrm{V}} \cdot(1+\cos \theta)$

The first one, the work of immersion, can be used to probe the evolution of the graphite/liquid interfacial tension providing that surface tension of solid graphite can be considered as nearly constant. Therefore, the work of immersion can give an estimate of adsorption phenomena occurring at the graphite/liquid interface. The work of adhesion is directly proportional to the strength of bonds established at the graphite/liquid interface and it could therefore also be used in order to investigate interfacial phenomena. As a conclusion, either of these two quantities can be used to evaluate the influence of additives on graphite/melt interfacial segregation.

Several of the above mentioned authors made the interesting experiment of adding "antispheroidizing" elements to the melt. As an example, the anti-spheroidizing effect of aluminum is illustrated in Fig. 8 where it is seen that adding 0.2 wt.\% Al leads to a significant amount of non-spheroidal graphite when there is very little in the reference alloy. McSwain and Bates [51] added $\mathrm{Bi}$ and $\mathrm{Sb}$ to un-spheroidized melts and observed a strong increase of the surface tension while the graphite remained lamellar. Selçuk and Kirkwood over-treated a melt with Ce leading to a strong increase in the surface tension while some of the spheroidal graphite degenerated to lamellar. Takita and Ueda [44] added $\mathrm{Pb}$ to alloys with 0.005 and 0.069 wt.\% $\mathrm{Mg}$. The surface tension of the liquid remained very high while graphite was lamellar in the former and partly lamellar in the latter alloy. Finally, Mil'man et al. made addition of Bi, Sb or Sn with or without Ce to Mg-treated melts. They observed either flake graphite or spheroidal graphite and reported surface tension that was higher for spheroidal graphite than for lamellar graphite. These authors added also aluminum to an un-treated melt and obtained a higher surface tension while graphite remained lamellar. 


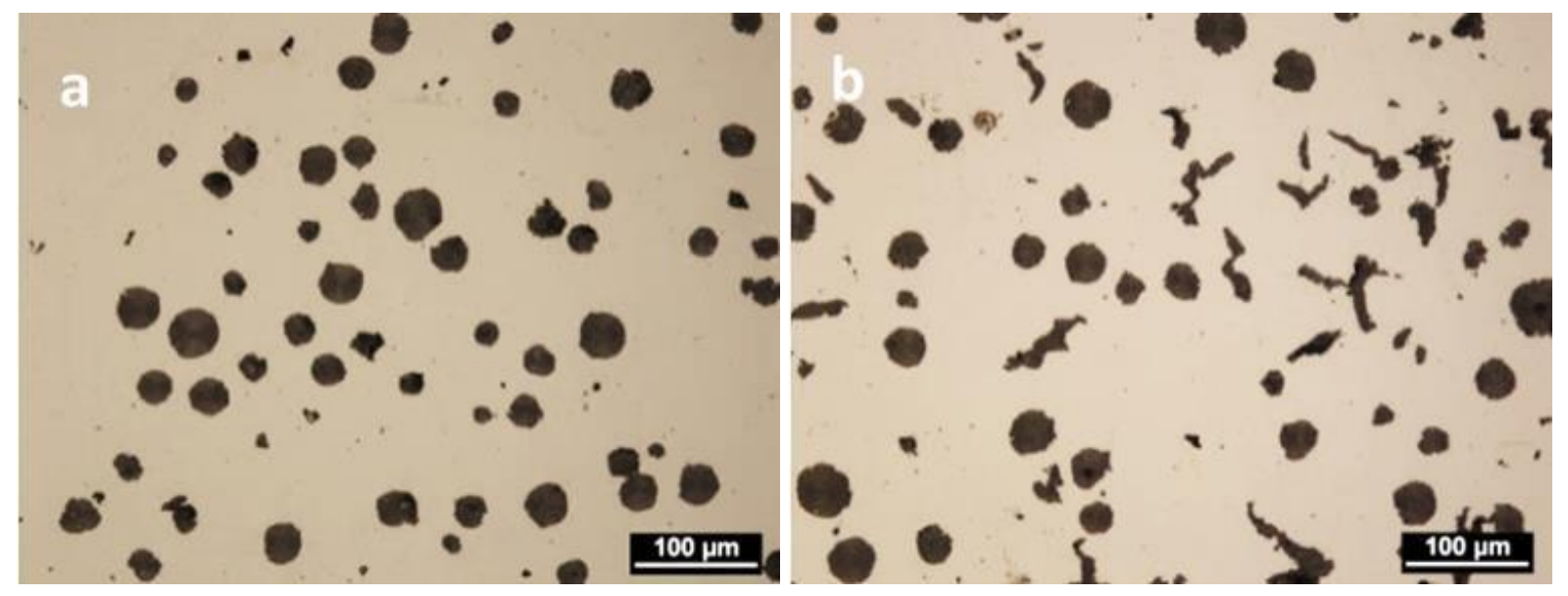

Figure 8. Microstructure of a spheroidal graphite cast iron without addition (a) and with 0.2 wt.\% Al added (b). The alloys were sand cast in a Y4 keel-block. Courtesy of J. Bourdie.

The results of Mil'man et al. show the same trends as other results and are the most numerous. They were thus selected to plot in Fig. 9 the values of $\mathrm{W}_{\mathrm{a}}$ versus the corresponding surface tension values of the liquid. In this graph, samples with lamellar graphite are represented with solid symbols and those with spheroidal graphite with open symbols. It is seen that un-treated melts show high $\mathrm{W}_{\mathrm{a}}$ value while melts containing $\mathrm{Mg}$ all show a low $\mathrm{W}_{\mathrm{a}}$ value, regardless of the graphite shape. Amongst these latter, those presenting lamellar graphite (within the ellipse) relate to relatively low surface tension while those with nodular graphite (open symbols) show high surface tension. Figure 8 also illustrates the effect of adding aluminum which increases the surface tension without changing the lamellar graphite shape. This figure clearly illustrates that measuring surface tension alone could not help to predict the graphite shape, while the simultaneous knowledge of two interfacial parameters such as surface tension and work of adhesion could contribute to determining the graphite shape.

The work of adhesion can also interestingly be compared with the cohesion of the iron melt that is equal to twice the $\sigma_{\mathrm{LV}}$ value. The work of adhesion thus represents about $10 \%$ of the cohesion of the melt for low sulfur activity spheroidized alloys but the ratio dramatically increases with sulfur activity giving a clear evidence of the increase of bond strength established between graphite and the melt. In summary, removing sulfur from the melt by adding $\mathrm{Mg}$ or Ce increases the surface tension but also decreases $\mathrm{W}_{\mathrm{a}}$, suggesting that the bonds between liquid and graphite are significantly weakened. Adding surface-active elements such as $\mathrm{Bi}, \mathrm{Sb}$ and $\mathrm{Sn}$, after the spheroidizing treatment leads to a decrease of the 
surface tension with little change of the contact angle, and thus to a small decrease in $\mathrm{W}_{\mathrm{a}}$. Mil'man et al. concluded that the effect of "anti-spheroidizers" is only on the surface tension of the melt, i.e., that they do not segregate at the graphite/liquid interface. Since Mil'man et al. published their work, evidencing Sb segregation at the graphite/matrix interface as described in the next section shows that this latter conclusion was wrong and it may be safely postulated that this applies also to Bi and Sn. In fact, Mil'man et al. observed a decrease by a factor of 1.5 of the surface tension with the addition of "anti-spheroidizing" elements. As a consequence, without any effect on the liquid-solid interfacial energy, one should expect a sharp increase of the contact angle. However, they report that "anti-spheroidizing" elements have a limited effect on contact angle, meaning that the expected increase is counter-balanced by a concomitant effect on the graphite/liquid interfacial energy, $\sigma^{\mathrm{Gra} / \mathrm{L}}$, that is also decreased.

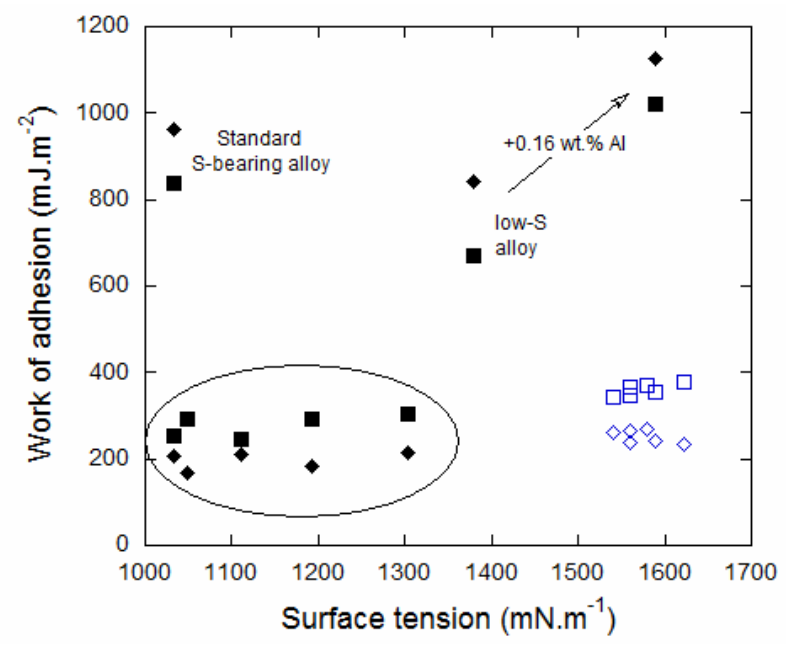

Figure 9. Work of adhesion as function of surface tension. Results picked up from the table 2 in Mil'man et al. [39]. Open symbols are for spheroidal graphite and solid symbols for lamellar graphite; squares are results on basal planes and diamonds on prism planes.

\subsection{Interfacial segregation}

One of the appropriate means to study interface segregation is certainly Auger analysis in spot and mapping modes. This has been applied with success to several of the most segregating elements in cast irons that were mentioned in the introduction of this paper, namely to $\mathrm{O}, \mathrm{S}$, 
$\mathrm{Sb}$ and Te. Johnson and Smartt [13] evidenced the presence of both oxygen and sulfur at the surface of a graphite flake in a cast iron containing $0.04 \mathrm{wt} . \% \mathrm{~S}$. From their Auger spectrum which shows also intense Fe peaks and little carbon, this should have been on the matrix side. By sputtering, the authors showed that this enrichment was limited to the surface (4-5 equivalent iron layers) and estimated the content of oxygen to 25 at. $\%$ and that of sulfur to 5 at.\%. An important insight was gained by Franklin and Stark [52] who performed a Secondary Ion Mass Spectroscopy (SIMS) profile through a flake in a cast iron containing $0.0065 \mathrm{wt} . \%$ $\mathrm{S}$. They found oxygen to be distributed uniformly within the bulk of the graphite precipitate with some higher level at the interface. In contrast, sulfur presented a $2 \mu \mathrm{m}$ periodicity they associated to the substructure of the flake. The authors suggested that this observation demonstrates oxygen adsorbs on the prismatic planes when sulfur does so preferentially on the basal planes.

Using samples obtained by quenching during directional solidification, Park and Verhoeven [53] investigated the distribution of oxygen and sulfur in flake and undercooled graphite of high purity and sulfur doped (0.02 wt.\% S added) Fe-3.4C-2Si alloy (wt.\%). The samples were fractured in the Auger apparatus to evidence a surface parallel to the growth direction. In flake-type graphite S-doped iron, the maps showed the iron side of graphite/matrix interface to be covered with a one atom thick layer of sulfur, with channels of oxygen crisscrossing the surface. It was easy to associate sulfur to the basal planes and oxygen to growth steps, i.e. prism planes. The oxygen coverage was thick (6-8 monolayers) with an associated shift of the $\mathrm{Fe}(46 \mathrm{eV})$ peak indicative of iron oxide. Performing experiments at various quenching rates and atmospheres, the authors concluded that the oxygen segregation mostly built up in solidstate with the oxygen atoms coming from the sample and not from the environment.

Furthermore, when the sulfur content of the iron was high enough for the sulfur to saturate the graphite matrix interface, oxygen segregation was limited to the prim planes of graphite at the growth ledges. If the sulfur content was decreased as in their high purity alloy, S and O were found lying in large adjacent patches along the graphite flakes, again on the matrix side.

For melt control before casting, thermal analysis with Te-bearing cups are often used which lead to solidification in the metastable system. For investigating the action of Te, Verhoeven et al. [8] carried out directional solidification experiments which quenching, changing the growth rate so as to shift from the stable to the metastable solidification. Auger analysis of samples with undercooled graphite, i.e., solidified at a growth rate just below the transition, 
showed the presence of a one atom layer of Te at the graphite-matrix interface, on the matrix side [54].

In spheroidal graphite cast irons, Sb enrichment has been observed with Auger analysis by Kovacs [10], Qiang et al. [55], Liu et al. [56] and Dekker et al. [11]. In agreement with Kovacs, Dekker et al. clearly showed that $\mathrm{Sb}$ is on the matrix side and not the graphite side of the interface, and that it was associated with some carbon and iron. A small amount of sulfur was also seen on the Auger spectrum of Dekker et al., in agreement with other reports [12, 57] as well as on iron alloys heat treated at $850^{\circ} \mathrm{C}$ and aged at $600^{\circ} \mathrm{C}$ [58]. Observation of the Auger records with $\mathrm{Sb}$ peak in the report by Liu et al. [56] shows also strong Fe peaks and no $\mathrm{C}$ peak suggesting $\mathrm{Sb}$ was also on the matrix side. Dekker et al. could simulate the Auger signal assuming two carbon layers and one Sb layer on top of the matrix. The total thickness of the surface layer was thus of the order of $1 \mathrm{~nm}$, though in some locations the Sb signal was weaker indicating the coverage may not have been homogeneous. This layer appeared anyway enough to limit spheroidal graphite growth during solidification [11] and to promote metastable eutectoid transformation of the matrix to pearlite [9], that is to say it hinders the transfer of carbon to graphite precipitates which would be necessary for the stable eutectoid transformation.

In summary, all four elements $\mathrm{O}, \mathrm{S}, \mathrm{Sb}$ and Te that are known to be strongly surface active in cast irons have been effectively found to segregate also at the graphite/matrix interface. The surface enrichment is as a one atom monolayer for $\mathrm{S}, \mathrm{Sb}$ and Te, and may be thicker for oxygen though apparently mostly resulting from solid-state diffusion upon cooling the material.

The most deceptive Auger results are certainly that magnesium could not be detected either within graphite or at the surface of graphite spheroids [12], leading Johnson et al. [13] to conclude that adsorption of spheroidizer is not necessary for modifying graphite shape. However, this could mean as well that the spatial distribution of $\mathrm{Mg}$ was such that it could not be detected with Auger. As a matter of fact, the detection limit of Auger is of the order of a couple of percent while much lower values may be reached with electron microprobe. With appropriate analysis conditions for microprobe analysis, Bourdie et al. [5] could effectively detect $\mathrm{Mg}$ within graphite and at the graphite-matrix interface of some spheroids and discuss other similar results. In fact, low level of $\mathrm{Mg}$ at the interface was detected after heat-treatment of the casting $[4,5]$ while it was not in the as-cast state, suggesting absorption of $\mathrm{Mg}$ during 
growth and later expulsion as graphite crystallinity increases. In the case of slow cooling casting, $\mathrm{Mg}$ could be detected within graphite and sometimes accumulated at the graphite matrix using EDS in a SEM on FIB thinned lamellae [59]. Using both atom probe and EDS in a TEM, Qing et al. showed the presence of many foreign elements in graphite amongst which $\mathrm{Mg}$ and $\mathrm{Ce}$ [60]. These results are in line with earlier works by Franklin [61] and Fidos [62, 63] who demonstrated that graphite in cast irons does contain foreign elements in amounts that are much larger for spheroidal graphite than for lamellar graphite. This shows that elements which are not surface active can anyway be absorbed in graphite after having been adsorbed at its surface.

\subsection{Shape of primary graphite}

It has been seen that the spheroidizing treatment of cast iron melts increases their surface tension, and this is due to the decrease of free sulfur and oxygen in the melt. This leads to the often used statement that spheroidal graphite will be obtained provided the melt has a high surface tension and lamellar graphite at low surface tension. However, it can be concluded from Fig. 9 that surface tension alone does not control graphite shape and that two interfacial parameters are required. The above statement has been extended to the graphite/liquid interface tension considering it scales with $\sigma^{\mathrm{L} / \mathrm{V}}$ if the surface tension of graphite is constant (eq. 6) as most often assumed. However, interfacial tension dictates the equilibrium shape of crystals, not the habit planes during their growth. In other words, one should not try to consider the change in the relative value of the interfacial tension between basal and prism planes to predict graphite shape.

The other school of thoughts to explain graphite shape considers the adsorption of elements at the graphite melt interface [12]. Elements that are surface active are expected to segregate to the graphite/matrix interface, whether the matrix is liquid or austenite. This parallel between surface and interface segregation stands on the relation established between surface tension and grain boundary segregation in steels and other alloys [64] which has been theorized [65, 66]. However, the graphite spheroidizers, $\mathrm{Mg}$ and $\mathrm{Ce}$, are not surface active and it has been seen that they do not show up as a film at the graphite/matrix interface.

The only cases where $\mathrm{Mg}$ could be detected at the graphite/matrix interface with Auger were when associated with $\mathrm{P}$ as $\mathrm{Mg}-\mathrm{P}$ compound, and also sometimes $\mathrm{S}$ as $\mathrm{Mg}-\mathrm{P}-\mathrm{S}$ compound [13]. 
Using EDS in an atomic resolution microscope, Domengès et al. could also observe compounds of $\mathrm{Mg}, \mathrm{Sn}$ and $\mathrm{Pb}$ at the interface between a spheroid and a protuberance [59]. The compounds observed in these studies are not expected to be stable at the temperature at which cast iron solidifies. It was thus conjectured that $\mathrm{Mg}$ and these other elements were in their elemental form at the surface of graphite when solidification completed and that they clustered during cooling down as postulated for some grain boundary precipitation of surface active elements in steels [65]. Together with the microprobe analyses reported above, these latter observations sustain the hypothesis that $\mathrm{Mg}$ and $\mathrm{Ce}$ act as a spheroidizer by adsorption at discrete places at the surface of graphite and not accumulated as a film.

The present review on the segregation of surface active elements suggests a schematic for the control of graphite shape that is more subtle than the previous approach limited to DFT calculations [7]. It has been seen that $\mathrm{S}$ segregates at the graphite/matrix interface and triggers a strong bonding between these phases. Because sulfur segregation relates first to basal planes, growth along the prismatic planes is strongly favored, giving lamellar graphite. If the free-S content, and thus its activity, in the melt is strongly decreased by adding spheroidizers, $\mathrm{Mg}$ and/or Ce, the bonds between graphite and matrix weakens. In that case, growth along the prismatic direction would be still favoured except if the spheroidizers adsorb on the prism planes and decrease their extension kinetics. In that case, growth along the basal direction can be preferred leading to spheroidal growth. Finally, adding "anti-spheroidizing" elements such as $\mathrm{Sb}$ or $\mathrm{Sn}$, and certainly also $\mathrm{Bi}$ and $\mathrm{Pb}$, to a spheroidized melt annihilates this effect of spheroidizers by repelling them in the bulk of the melt, leading to spheroidal graphite degeneracies that grow as lamellar graphite does.

\section{Conclusion}

Using literature data mostly on iron binary alloys, an expression of the surface tension was obtained that accounts of elements relevant for cast irons. Most of the available results were obtained for temperature higher than $1450^{\circ} \mathrm{C}$ and were here extended to temperature down to the eutectic reaction at less than $1200^{\circ} \mathrm{C}$. The surface tension values thus predicted were found to satisfactorily agree with values reported for cast irons. The role of sulfur and of the effect of the thermodynamic interactions between carbon and sulfur have been pin pointed 
and it clearly appears that experiments on carbon saturated $\mathrm{Fe}-\mathrm{C}-\mathrm{S}$ melts in the $1200^{\circ} \mathrm{C}$ $1500^{\circ} \mathrm{C}$ would be highly welcome.

Most of the experiments dedicated to cast iron surface tension that have been reported in the literature were carried using the sessile drop technique onto graphite substrates. The results show that desulfurization of the melt by adding $\mathrm{Mg}$ or Ce leads to an increase of the surface tension and of the contact angle at the triple line. By virtue of Young's equation, this shows

that either or both of $\sigma^{\mathrm{Gra} / \mathrm{L}}$ and $\sigma^{\mathrm{Gra} / \mathrm{V}}$ have also been affected and the practical consequence is that there is no unique relation between cast iron surface tension and graphite shape.

To analyze the properties of the graphite/melt interface, the work of adhesion has been introduced which is very high for sulfur-bearing alloys and quite low for alloys that have been spheroidized with Mg and/or Ce. Finally, available information on the segregation of foreign elements at the graphite/matrix interface is reviewed and it is pointed out that elements known to be highly surface reactive on iron melts are likely to segregate at this interface. All this gives some additional insights into the mechanism of graphite spheroidization in cast irons and the degeneration of spheroidal graphite when trace elements such as Sb or Sn are added.

\section{Acknowledgments}

We are indebted with several colleagues, amongst whom Michael Vynnycky (Uni. Leicester) who provided a translation of the paper by Kawai et al. [33] and Jin Cheng Liu for translation of the most important information of the paper Song Qiang et al. [55]. We are also pleased to acknowledge the support of TCAB with the provision of the TCFE-11 database for enough time to carry out the necessary calculations.

Conflict of interest: The authors declare that they have no conflict of interest.

\section{References}

[1] R. Suárez, J. Sertucha, P. Larrañaga and J. Lacaze: Metall. Mater. Trans. B, 2016, vol. 47B, pp. 2744-2753. 
[2] K. Basutkar, C.S. Park, R.E. Miller and C.R. Loper: AFS Trans., 1973, vol. 80, pp. 180184

[3] H. Itofuji and H. Uchikawa, AFS Trans., 1990, vol. 98, pp 429-448.

[4] P. Dierickx, C. Verdu, A. Reynaud and R. Fougères: Scr. Mater., 1996, vol. 34, pp. 261268.

[5] J. Bourdie, F. Bruneseaux, P. de Parseval, S. Gouy, L. Laffont and J. Lacaze: Mater. Sci. Forum, 2018, vol. 925, pp. 20-27.

[6] A. Javaid and C.R. Loper: AFS Trans., 1995, vol. 103, pp. 135-150

[7] J. Lacaze, D. Connétable and M.J. Castro de Roman: Materialia, 2019, vol. 8, 100471.

[8] J.D. Verhoeven, J.S. Park and L.L. Jones: Metall. Trans. A, 1989, vol. 20A, pp 1867-1873.

[9] B.C. Liu, T.X. Li, Z.J. Rue, X.Y. Yang, E.Q. Huo and C.R. Loper: AFS Trans., 1990, vol. 98, pp. 753-757.

[10] B.V. Kovacs: AFS Trans., 1980, vol. 89, pp. 79-96

[11] L. Dekker, B. Tonn and G. Lilienkamp: Int. J. Metalcast., 2020, vol. 14, pp. 827-835.

[12] W.C. Johnson, B.V. Kovacs and J.A. Clum: Scr. Metal., 1974, vol. 8, pp. 1309-1316

[13] W.C. Johnson and H.B. Smartt: Scr. Metal., 1975, vol. 9, pp. 1205-1210.

[14] H. Muhammad Muhmond and H. Fredriksson: Metall. Mater. Trans. A, 2014, vol. 45A, pp. 6187-6199

[15] P. Kozakevitch, S. Chatel, G. Urbain and M. Sage: Rev. Métall., 1955, vol. 52, pp. 139160

[16] I. Egry, E. Ricci, R. Novakovic and S. Ozawa: Adv. Collod. Interface Sci., 2010, vol. 159, pp. 198-212.

[17] P. Kozakevitch and G. Urbain: Mem. Sci. Rev. Metall., 1961, vol. 58, pp. 401-413.

[18] K.C. Mills and Y.C. Su: Inter. Mater. Rev., 2006, vol. 51, pp. 329-351.

[19] T. Yoshikawa: Mater. Trans., 2013, vol. 54, pp. 1968-1974.

[20] B.J. Keene: Int. Mater. Rev., 1988, vol. 33, pp. 1-37.

[21] P. Kozakevitch and G. Urbain: Mem. Sci. Rev. Metall., 1961, vol. 58, pp. 517-534

[22] P. Kozakevitch and G. Urbain: Mem. Sci. Rev. Metall., 1961, vol. 58, pp. 931-947.

[23] F.A. Halden and W.D. Kingery: J. Phys. Chem., 1955, vol. 59, pp. 557-559.

[24] K. Nogi and K. Ogino: Can. Metall. Q., 1983, vol. 22, pp. 19-28

[25] G.R. Belton: Metall. Trans. B, 1976, vol. 7B, pp. 35-42.

[26] C.H.P. Lupis, Chemical thermodynamics of materials, North-Holland, New-York, 1983, PP. 389-435.

[27] I. Seyhan and I. Egry:, Int. J. Thermophys., 1999, vol. 20, pp. 1017-1028. 
[28] K. Morohoshi, M. Uchikoshi, M. Isshiki and H. Fukuyama: ISIJ Int., 2011, vol. 51, pp. $1580-1586$.

[29] M. Divakar, J.P. Hajra, A. Jakobsson and S. Seetharaman: Metall. Mater. Trans. B, 2000, vol. 31B, pp. 267-276.

[30] Y. Chung and A.W. Cramb: Metall. Mater. Trans. B, 2000, vol. 31B, pp. 957-971.

[31] J.P. Hajra and M. Divakar: Metall. Mater. Trans. B, 1996, vol. 27B, pp. 241-253.

[32] B.J. Keene, K.C. Mills, J.W. Bryant and E.D. Hondros: Can. Metall. Q., 1982, vol. 21, pp. 393-403.

[33] Y. Kawai, K. Mori and M. Kishimoto: Tetsu-to-hagane, 1974, vol. 60, pp. 29-37.

[34] T.J. Whalen, S.M. Kaufman and M. Humenik: Transactions of the ASM, 1962, vol. 55, pp. 778-785.

[35] G.R. Belton: Metall. Trans., 1972, vol. 3, pp. 1465-1469.

[36] K.I. Vashchenko and A.P. Rudoi: Russian Casting Production, 1962, pp. 272-275.

[37] E. Selçuk and D.H. Kirkwood: J. Iron Steel Inst., 1973, pp. 134-140.

[38] F. Mampaey, D. Habets, J. Plessers and F. Seutens: Int. J. Metalcast., 2010, vol. 10, pp. $25-43$.

[39] B.S. Mil'man, N.N. Aleksandrov, V.T. Solenkov and L.V. Il'icheva: Russian Casting Production, 1976, pp. 179-182.

[40] https://thermocalc.com/products/databases/ accessed June 27, 2021

[41] K.I. Vashchenko, K.K. Kosnyanu and V.Ya. Zhuk: Russian Casting Production, 1966, pp. $72-74$.

[42] E. Ricci, D. Giuranno and N. Sobczach: J. Mater. Eng. Perform., 2013, vol. 22, pp. $3381-3388$.

[43] R.H. McSwain, C.E. Bates and W.D. Scott: Cast Met. Res. J., 1974, vol. 10, pp. 181-190. [44] M. Takita and Y. Ueda: Mater. Trans. JIM, 1979, vol. 20, pp. 569-576.

[45] N. Eustathopoulos, M.G. Nicholas and B. Drevet, Wettability at high temperatures, Pergamon, 1999

[46] N. Eustathopoulos, N. Sobczak, A. Passerone and K. Nogi: J. Mater. Sci., 2005, vol. 40, pp. $2271-2280$.

[47] S. Jung, T. Ishikawa and H. Nakae: Mater. Sci. Eng. A, 2008, vol. 476, pp. 350-356.

[48] O. Dezellus and N. Eustathopoulos: Scr. Mater., 1999, vol. 40, pp. 1283-1288.

[49] A.N. Roviglione and J.D. Hermida: Metall. Mater. Trans. B, 2004, vol. 35B, pp. 313330.

[50] S.K. Rhee: J. Am. Ceram. Soc., 1972, vol. 55, pp. 300-303. 
[51] R.H. McSwain and C.E. Bates, The metallurgy of cast iron, Georgi Ed., Saint-Saphorin, 1975, pp. 423-440.

[52] S.E. Franklin and R.A. Stark: E-MRS Symp. Proc., 1985, vol. 34, pp. 25-35.

[53] J.S. Park and J.D. Verhoeven: Metall. Mater. Trans. A, 1996, vol. 27A, pp. 2740-2753.

[54] J.D. Verhoeven, A.J. Bevolo and J.S. Park: Metall. Trans. A, 1989, vol. 20A, pp. 8751881.

[55] Song Qiang, Yang Jiarong and Liu Gengnan: Journal of Zhejiang University (Natural Science), 1987, vol. 4, pp. 67-76.

[56] B.C. Liu, T.X. Li, Z.J. Rue, X.Y. Yang, E.Q. Huo and C.R. Loper: AFS Trans., 1990, vol. 98, pp. 753-757.

[57] Q. Ziqiang and Y. Zongsen: Acta Metallurgica Sinica B, 1989, vol. 2, pp. 202-204.

[58] R.H. Jones, D.R. Baer, L.A. Charlot and M.T. Thomas: Metall. Trans. A, 1988, vol. 19, pp. 2005-2011.

[59] B. Domengès, M. Martinez Celis, F. Moisy, J. Lacaze and B. Tonn: Carbon, 2021, vol. 172, pp. 532-541.

[60] J. Qing, M. Xu and V. Pikhovich: Int. J. Metalcast., 2020, vol. 14, pp. 1115-1122.

[61] B. Francis: Metall. Trans., 1979, vol. 10, pp. 21-31.

[62] H. Fidos: FWP J., 1977, vol. 17, pp. 39-54.

[63] H. Fidos: FWP J., 1982, vol. 22, pp. 43-62.

[64] M.P. Seah and C. Lea: Philos. Mag., 1975, vol. 31, pp. 627-645.

[65] M. Guttmann: Metall. Trans. A, 1977, vol. 8A, pp. 1383-1401.

[66] P. Wynblatt and D. Chatain: Metall. Mater. Trans. A, 2006, vol. 37, pp. 2595-2620.

[70] P. Sahoo, T. Debroy and M.J. McNallan: Metall. Mater. Trans. B, 1988, vol. 19B, pp. 483-491.

[71] J.P. Hajra and M. Divakar, Metall. Mater. Trans. B, 1996, vol. 27B, pp. 241-253.

[72] I. Jimbo and A.W. Cramb, ISIJ Int., 1992, vol. 32, pp. 26-35.

[73] I. Jimbo and A.W. Cramb: Metall. Mater. Trans. B, 1993, vol. 24B, pp. 5-10.

[74] J. Lee and K. Morita: ISIJ Int., 2002, vol. 42, pp. 588-594.

[75] A. Abbasalizadeh, L. Muhmood, A. Danaei, Y.D. Yang, M. Barati, A. McLean and S. Seetharaman, A sessile drop study of iron-carbon-sulfur alloys on an alumina substrate. (published by semanticscholars.org), www.pyrometallurgy.co.za/MoltenSlags2012/w108.pdf. Accessed 27 June 2021

[76] B.C. Allen and W.D. Kingery: Trans. Metall. Soc. AIME, 1959, vol. 215, pp. 30-37.

[77] M.J. McNallan and T. Debroy: Metall. Mater. Trans. B, 1991, vol. 22B, pp. 557-560. 


\section{Appendix 1 - Effect of oxygen on the surface tension of iron.}

Morohoshi et al. [28] have measured the surface tension of iron and the effect of oxygen activity using an electro-magnetic levitation (EML) experimental set-up for temperature in the range 1500 to $1800^{\circ} \mathrm{C}(1773$ to $2073 \mathrm{~K})$. They expressed $\sigma^{\mathrm{L} / \mathrm{V}}\left[\mathrm{mN} \cdot \mathrm{m}^{-1}\right]$ as:

$$
\sigma^{\mathrm{L} / \mathrm{V}}=\sigma_{\mathrm{Fe}}^{\mathrm{L} / \mathrm{V}}-\mathrm{R} \cdot \mathrm{T}_{\mathrm{K}} \cdot \Gamma_{\mathrm{O}}^{\mathrm{sat}} \cdot \ln \left(1+\mathrm{K}_{\mathrm{ad}} \cdot \mathrm{a}_{\mathrm{O}}\right)
$$

where $\sigma_{\mathrm{Fe}}^{\mathrm{L} / \mathrm{V}}$ was evaluated as $1925-0.455 \cdot\left(\mathrm{T}_{\mathrm{K}}-1808\right)\left[\mathrm{mN} \cdot \mathrm{m}^{-1}\right]$, and $\Gamma_{\mathrm{O}}^{\mathrm{sat}}$ was set to $18.6 \cdot 10^{-6}$ $\mathrm{mol} \cdot \mathrm{m}^{-2}$ which is well in the range of literature data reviewed by the authors. The activity $\mathrm{a}_{\mathrm{O}}$ was expressed with reference to pure oxygen gas at the current temperature. Morohoshi et al. also evaluated the standard enthalpy of oxygen adsorption, $\Delta_{\text {ads }} \mathrm{H}_{\mathrm{O}}$, at $355 \mathrm{~kJ} \cdot \mathrm{mol}^{-1}$ from measurements at various temperatures. Using van't Hoff's equation then led them to the following expression:

$$
\mathrm{K}_{\mathrm{ads}}=4.11 \cdot 10^{-5} \cdot \exp \left(\frac{355000}{\mathrm{R} \cdot \mathrm{T}_{\mathrm{K}}}\right)
$$

valid for the temperature interval $1500-1800^{\circ} \mathrm{C}(1773-2073 \mathrm{~K})$.

The effect of oxygen content on the surface tension at $1823 \mathrm{~K}$ calculated with eq. (A1) is shown with the interrupted line in Fig. A1 where it is compared to data from Kozakevitch and Urbain [21] and Morogoshi et al. [28], as well as data from Takiuchi et al. selected and listed by Divakar et al. [29]. In the work by Kozakevitch and Urbain, two series of experiments were reported in their Tables I and II that were aimed at checking possible biases in the methodology and are seen to agree very well between each other. Data by Morogoshi et al. was picked up from their table 2 and seem to show too high values as often observed with EML experiments [18]. The results selected by Divakar et al. show the same curvature as the results of Kozakevitch and Urbain, but with a shift to higher values which may well be due to the fact that the $\sigma_{\mathrm{Fe}}^{\mathrm{L} / \mathrm{V}}$ value considered by the authors surpasses by about $60 \mathrm{mN} \cdot \mathrm{m}^{-1}$ the assessed value (eq. 1 of the main text).

The value of $\Delta_{\mathrm{ads}} \mathrm{H}_{\mathrm{O}}$ of $-355 \mathrm{~kJ} \cdot \mathrm{mol}^{-1}$ in eq. (A2) is in the range of values found for chemisorption [26], but yet much higher than the $-146.3 \mathrm{~kJ} \cdot \mathrm{mol}^{-1}$ determined by Sahoo et al. 
[70]. This latter value of $-146.3 \mathrm{~kJ} \cdot \mathrm{mol}^{-1}$, as well as other similar values, has been adopted in many research works dedicated to temperatures related to steel elaboration [71] but seems to be based on very few results [70]. It was thus decided to rely on the more extensive work by Morohoshi et al. and to only correct eq. (A1) for using the expression of $\sigma_{\mathrm{Fe}}^{\mathrm{L} / \mathrm{V}}$ assessed by Mills and Su [18] (eq. 1 in the main text). We thus arrived at the following expression of $\sigma^{\mathrm{L} / \mathrm{V}}\left(\mathrm{mN} \cdot \mathrm{m}^{-1}\right)$ :

$\sigma^{\mathrm{L} / \mathrm{V}}=1880-0.41 \cdot\left(\mathrm{T}_{\mathrm{K}}-1811\right)-0.153 \cdot \mathrm{T}_{\mathrm{K}} \cdot \ln \left(1+4 \cdot 10^{-5} \cdot \exp \left(\frac{355000}{\mathrm{R} \cdot \mathrm{T}_{\mathrm{K}}}\right) \cdot \mathrm{a}_{\mathrm{O}}\right)$

where $a_{O}$ is the activity of oxygen with pure oxygen gas at the temperature $T_{K}$ as reference and was calculated using the TCFE-8 database of Thermocalc [40]. This gives the solid line in Fig. A1 which shows also an excellent agreement with the experimental results from Kozakevitch et al. [21].

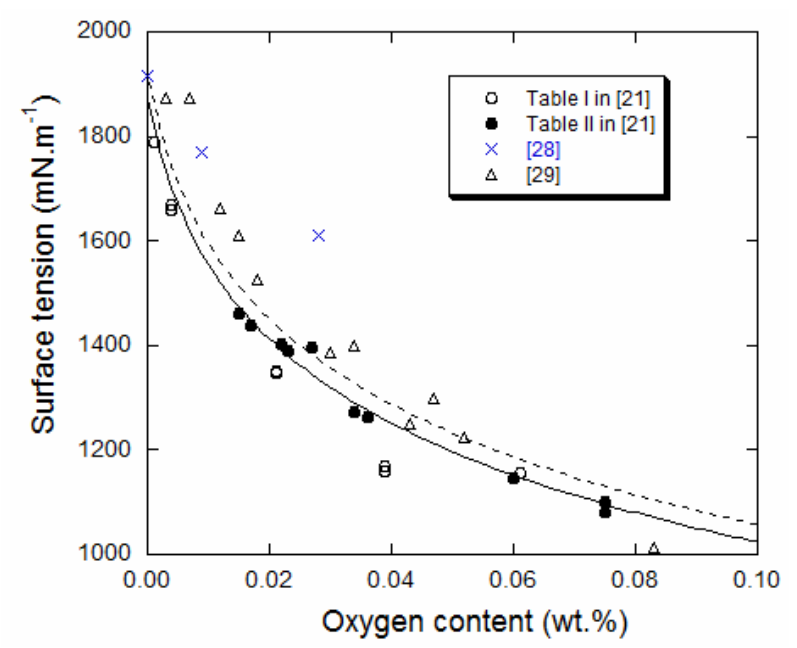

Figure A1. Change of surface tension of liquid iron with oxygen content. Symbols represent experimental measurements from Kozakevitch and Urbain [21], Morohoshi et al. [28] and Takiuchi et al. [29] at $1550{ }^{\circ} \mathrm{C}$. The interrupted line shows the calculated surface tension using eq. (A1) [28] and the solid line using eq. (A3) proposed in this work. 


\section{Appendix II - Effect of carbon on the surface tension of iron.}

Keene [20] noticed in his review that it has been reported no, positive and negative effect of carbon, and concluded that it is probable that increasing $\mathrm{C}$ content has only a small effect as otherwise it would be difficult to account for the results which find small change of the surface tension with carbon. In his review, Keene lists also various theories that have been mentioned to explain the changes observed. According to Kozakevitch et al. [15], the most probable reason for these large discrepancies is the presence of impurities, in particular oxygen and sulfur. Upon heating, carbon will assist deoxidizing of the melt which might explain the positive change of surface tension observed by some authors up to $1550-1600^{\circ} \mathrm{C}$ (1823-1873 K). Similarly, activity of sulfur is increased by carbon and thus leads to a decrease of the surface tension which scales with the increase in carbon content.

In more recent works on surface tension of iron and steels, one can find some measures showing an increase of surface tension with addition of carbon. Jimbo and Cramb [72] report the surface tension at $1550^{\circ} \mathrm{C}$ for two $\mathrm{Fe}-\mathrm{C}$ alloys, with about 2 and 4 wt. $\%$ carbon. Their value for pure iron is in the upper range of the data reviewed by Mills and $\mathrm{Su}$ [18] which is apparently due to a choice of iron density at $7.127 \mathrm{~g} \cdot \mathrm{cm}^{-3}$ at $1550^{\circ} \mathrm{C}(1823 \mathrm{~K})$ that is larger than the value assessed with eq. 2 of the main text. This overestimation applies similarly to their $\mathrm{Fe}-\mathrm{C}$ alloys if they used the equation giving the density of $\mathrm{Fe}-\mathrm{C}$ liquid alloys as function of carbon content that they derived in a previous work [73]. Another value is due to Lee and Morita [74] who used the same equation for the density, and this might explain in part why they obtained a so high value of $2138 \mathrm{mN} \cdot \mathrm{m}^{-1}$ for a $\mathrm{Fe}-3.55 \mathrm{wt} . \% \mathrm{C}$ alloy at $1550^{\circ} \mathrm{C}(1823$ K). More recently, Abbasalizadeh et al. [75] reported results on four Fe-C-S alloys containing 0.03-0.037 wt.\% S and 0.5-4 wt.\% C. For preparing the Fe-C-S alloys, a Fe-S alloy was mixed with a Fe-C alloy and prepared by holding the mixture at $1873 \mathrm{~K}$ for height hours in sealed alumina crucible. At that temperature and for such a long time, one expects some alumina dissolved in the melt and oxygen content after experiments should have been reported. Hence the increase of the surface tension with increased carbon content that the authors reported might well be due to release of $\mathrm{CO}$ gas during surface tension measurements, i.e. a decrease of the oxygen content of the melt.

In these instances, it is worth describing the work by Allen and Kingery [76] who reported results for iron (0.01 wt.\% O, 0.005 wt.\% $\mathrm{C}$ and 0.005 wt.\% S) and Fe-3.9wt.\%C alloy (0.001 wt. $\% \mathrm{O}$ and 0.005 wt. $\% \mathrm{~S})$ in vacuum for temperature lower than $1550^{\circ} \mathrm{C}(1823 \mathrm{~K})$ and under 
helium above this temperature. They found a clear difference for the surface tension measured, on the one hand, upon heating and holding at temperature and, on the other hand, after melting at high temperature and cooling before measurement. In Fig. A2, the bold line represents the reference for pure iron (eq. 1) and the thin line the results of Allen and Kingery upon first heating. The symbols for temperature at and above $1500^{\circ} \mathrm{C}(1773 \mathrm{~K})$ are for results under helium upon first heating, while those at and below $1400^{\circ} \mathrm{C}(1673 \mathrm{~K})$ are for experiments under vacuum after melting at $1500^{\circ} \mathrm{C}$. Because the results for iron were below those for the Fe-C alloy, in agreement with the fact that the former contained a high level of oxygen, the authors concluded that heating under helium did not remove impurities from the melt. On the contrary, melting under vacuum was effective and showed a clear increase of the surface tension for temperatures lower than $1400^{\circ} \mathrm{C}(1673 \mathrm{~K})$ when compared to values obtained upon simple heating.

Interestingly enough, the results under vacuum for temperature between $1200^{\circ} \mathrm{C}$ and $1400^{\circ} \mathrm{C}$ (1473 and $1673 \mathrm{~K})$ appear in close agreement with eq. 1 extrapolated down to $1200^{\circ} \mathrm{C}(1473$ K). This strongly suggests that carbon has no effect on the surface tension of iron and that eq. 1 can be used as a reference for pure $\mathrm{Fe}-\mathrm{C}$ alloys down to eutectic temperature.

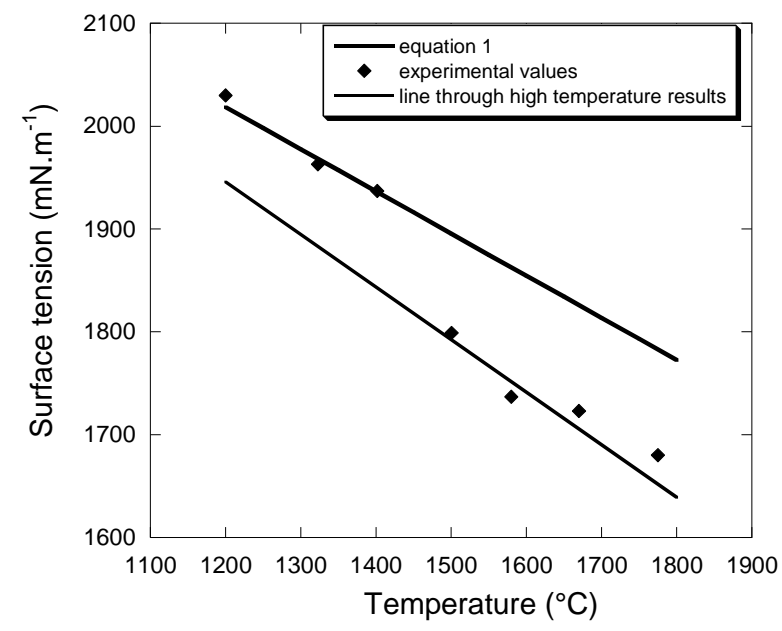

Figure A2. Symbols represent experimental data obtained by Allen and Kingery [76]. Experiments at $1500^{\circ} \mathrm{C}$ and above were performed under helium, those at lower temperature under vacuum. The thick line represents eq. 1 of the main text that gives the surface tension of pure iron, the thin line is a fit through the high temperature experimental data obtained on heating. 


\section{Appendix III - Effect of sulfur on the surface tension of iron.}

This appendix follows the same lines as Belton [25] and makes use also of the experimental results of Kozakevitch and Urbain [21] at $1550^{\circ} \mathrm{C}(1823 \mathrm{~K})$ and Kozakevitch et al. [15] at $1450^{\circ} \mathrm{C}(1723 \mathrm{~K})$. The results at $1550^{\circ} \mathrm{C}$ were obtained on both $\mathrm{Fe}-\mathrm{S}$ alloys and Fe-C-S alloys while those at $1450^{\circ} \mathrm{C}$ were obtained on Fe-C-S alloys, with $1.25,2.2$ and 4.0 wt.\% carbon. At given temperature, Kozakevitch et al. noticed that all their results follow the same curve when plotted as function of sulfur activity, and concluded that the role of carbon would be limited to its increase of the sulfur activity, with carbon rejected out of the surface layer by the surface active sulfur. Using this data, Belton obtained the following equation describing the effect of sulfur on the surface tension $\left(\mathrm{mN} \cdot \mathrm{m}^{-1}\right)$ of $\mathrm{Fe}$ at $1550^{\circ} \mathrm{C}(1823 \mathrm{~K})$ :

$$
\sigma=1788-195 \cdot \ln \left(1+185 \cdot \mathrm{a}_{\mathrm{S}}^{0}\right)
$$

in which $a_{S}^{0}$ is the activity of sulfur with reference at infinite dilution.

Selecting the results for $2.2 \mathrm{wt} . \% \mathrm{C}$, Belton then got for $1450^{\circ} \mathrm{C}(1723 \mathrm{~K})$ :

$$
\sigma=1765-184 \cdot \ln \left(1+325 \cdot \mathrm{a}_{\mathrm{S}}^{0}\right)
$$

Belton considered that the saturation coverage $\Gamma_{\mathrm{S}}^{\mathrm{sat}}$ would not change with temperature and adopted a value of $12.8 \cdot 10^{-6} \mathrm{~mol} . \mathrm{m}^{-2}$. From the effect of temperature, Belton evaluated the enthalpy of adsorption to $-147 \mathrm{~kJ} \cdot \mathrm{mol}^{-1}$. This value is close to that evaluated by Sahoo et al.

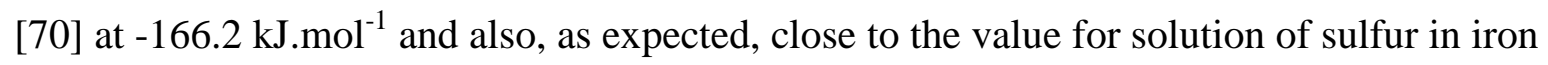
which was selected to $-135 \mathrm{~kJ} \cdot \mathrm{mol}^{-1}$ by McNallan and Debroy [77].

According to eq. 1 in the main text, the value of the surface tension for pure iron should be $1875 \mathrm{mN} \cdot \mathrm{m}^{-1}$ instead of $1788 \mathrm{mN} \cdot \mathrm{m}^{-1}$ at $1550^{\circ} \mathrm{C}(1823 \mathrm{~K})$ (eq. A4), and $1916 \mathrm{mN} \cdot \mathrm{m}^{-1}$ instead of $1765 \mathrm{mN} \cdot \mathrm{m}^{-1}$ at $1450^{\circ} \mathrm{C}(1723 \mathrm{~K})$ (eq. (A5)). Using eq. (A3), these differences could be accounted for by the presence of some oxygen, evaluated at less than $0.001 \mathrm{wt} . \%$ by Kozakevitch et al. However, carbon is expected to deoxidise the melt so that it would be better to use eq. 1 (main text) for the surface tension of pure iron. Doing so and using the van't Hoff's equation led to a much larger value for heat of adsorption of sulfur at $-232 \mathrm{~kJ} \cdot \mathrm{mol}^{-1}$. The surface tension of Fe-S alloys could then be written: 


$$
\sigma=1880-0.41 \cdot\left(\mathrm{T}_{\mathrm{K}}-1811\right)-0.107 \cdot \mathrm{T}_{\mathrm{K}} \cdot \ln \left(1+0.03 \cdot \exp \left(\frac{232000}{\mathrm{R} \cdot \mathrm{T}_{\mathrm{K}}}\right) \cdot \mathrm{a}_{\mathrm{S}}\right)
$$

where $a_{S}$ is the activity of sulfur with pure sulfur in gas state as reference.

The activity of sulfur was calculated with the TCFE-11 database and introduced in eq. (A6). The results are displayed in Fig. A3 where it is seen that the predictions for Fe-S alloys at $1550^{\circ} \mathrm{C}(1823 \mathrm{~K})$ fit very well the experimental data. At $1450^{\circ} \mathrm{C}(1723 \mathrm{~K})$, the differences between the three calculated curves reproduce well the experimental effect of carbon content.

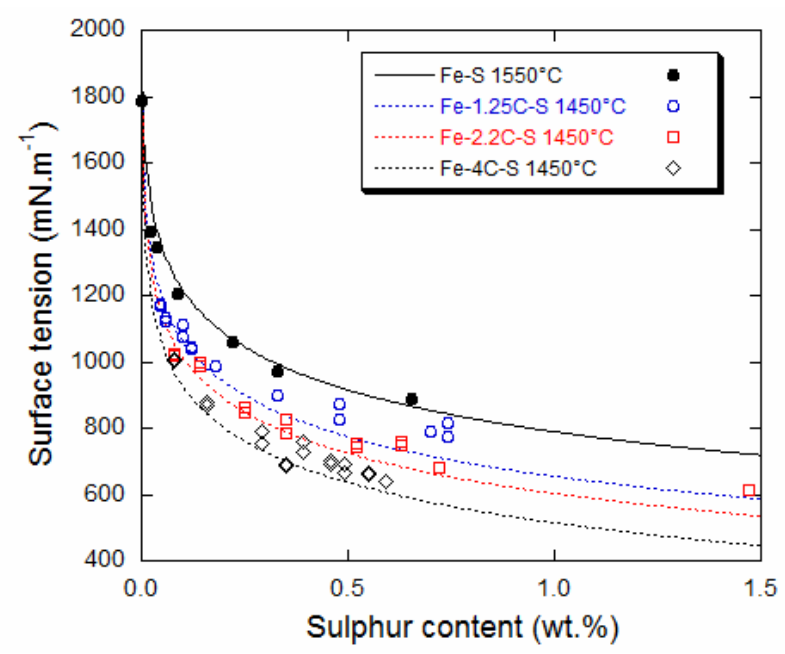

Figure A3. Symbols represent experimental results from Kozakevitch et al. [15] for Fe-S alloys $\left(1550^{\circ} \mathrm{C}\right)$ and $\mathrm{Fe}-\mathrm{C}-\mathrm{S}$ alloys $\left(1450^{\circ} \mathrm{C}\right)$. Lines are calculated with eq. (A6).

Lee and Morita [74] developed a model accounting for the formation of FeS associates at the surface but also concluded that calculations based on the simple atom monolayer model deviate little from it. Their experimental results on Fe-S alloys with up to $0.06 \mathrm{wt} . \% \mathrm{~S}$ and containing $60 \mathrm{ppm}$ oxygen at $1550^{\circ} \mathrm{C}(1823 \mathrm{~K})$ agree perfectly with those plotted in Fig. A3. Divakar et al. [29] selected data in the literature to describe the combined effect of carbon and sulfur on the surface tension of iron at $1550^{\circ} \mathrm{C}$ and $1600^{\circ} \mathrm{C}$. For measurements at $1550^{\circ} \mathrm{C}$, the alloys contained between 0.004 and $0.076 \mathrm{wt} . \% \mathrm{~S}$, and the carbon content varied up to 4.6 wt. $\%$. At $1600^{\circ} \mathrm{C}$, only results for 0.003 and $0.005 \mathrm{wt} . \% \mathrm{~S}$ were reported. These values are plotted in Fig. A4 where they are compared with predictions using eq. (A6) assuming no effect of carbon on the surface tension and with sulfur activity calculated using TCFE- 11 . 
Though there are some differences between calculated and experimental values, the trends are well reproduced.

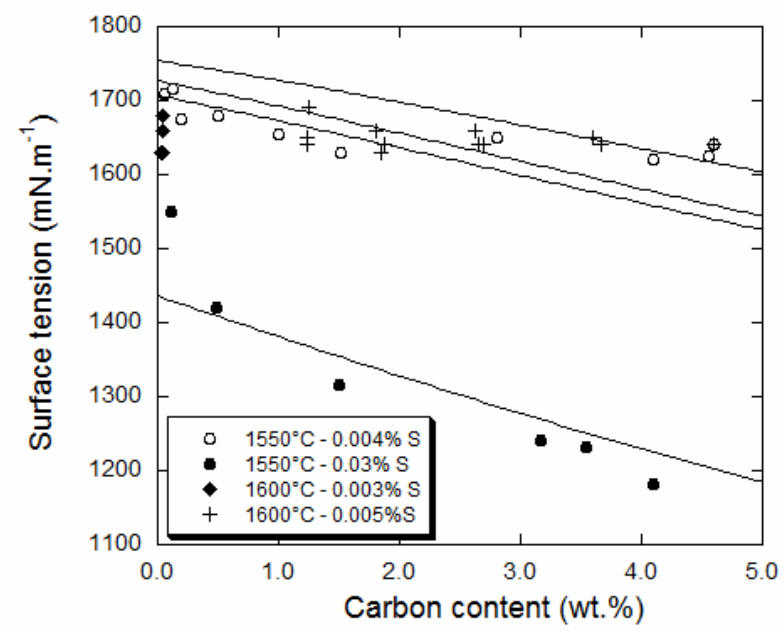

Figure A4. Effect of carbon on the surface tension of Fe-S alloys at various levels of sulfur. Experimental results were those selected by Divakar et al. [29], lines are calculated with eq. (A6). 


\section{Appendix IV}

This appendix shortly presents experimental results from literature that are used in the main text. When the sulfur content was indicated, the activity of sulfur as was calculated using the TCFE-11 database [40] with pure sulfur in gas state at the current temperature as reference.

Kozakevitch et al. [15] reported a series of surface tension values for cast irons found in the literature (their Table III). From these values, those corresponding to high phosphorus content (>1.86 wt.\%) have been excluded as not being representative of modern irons. All other values were selected and are listed in Table II together with the composition of the alloys and the temperature of measurement The last two alloys in the table have been nodularized but the $\mathrm{Mg}$ content was not given; a residual $\mathrm{Mg}$ content of $0.04 \mathrm{wt} . \%$ was assumed for calculating the sulfur activity and $\mathrm{MgS}$ precipitation was predicted for the first of these two alloys.

Using the sessile drop technique, McSwain et al. measured the surface tension, the contact angle and the interface tension of synthetic cast irons at $1200^{\circ} \mathrm{C}$. The graphite support was either pyrolytic or polycrystalline graphite. The pyrolytic graphite was orientated so as to have either the basal or prism planes facing the sample. McSwain et al. investigated the effect of $\mathrm{S}, \mathrm{Mg}$ and $\mathrm{Ce}$ [43] and of $\mathrm{Bi}$ and $\mathrm{Sb}$ [51]. Their data are reported in Table III where is noticed that a small change in surface tension as a function of graphite orientation, which appears curious.

Selçuk and Kirkwood [37] conducted a study on the effect of $\mathrm{Mg}$ and Ce on the surface tension of near eutectic Fe-C-Si alloys with 2.5-2.6 wt.\% Si. They qualified both their experimental device and their process by measuring the surface tension of pure copper. The experiments were carried out at $10^{\circ} \mathrm{C}$ superheat above the apparent melting temperature, i.e. in between $1180^{\circ} \mathrm{C}$ and $1215^{\circ} \mathrm{C}$ depending on the alloy. The evolution of the drop was followed during up to $60 \mathrm{~min}$ during which the melt composition could evolve by loss of $\mathrm{S}$ for the alloy without addition, and of $\mathrm{Mg}$ or Ce for the alloys with $\mathrm{Mg}$ or Ce addition, respectively. With an excess of cerium in a further experiment, the surface tension was found to rise to about $1900 \mathrm{~mJ} \cdot \mathrm{m}^{-1}$, a value approaching that for pure iron according to the authors though it should be $2012 \mathrm{~mJ} \cdot \mathrm{m}^{-1}$ according to eq. 1. It was noticed that graphite nodularity was affected by this excess in cerium. In table IV are listed the start and end compositions, surface tension and contact angle values, as well as the calculated sulfur activity. $\mathrm{Mg}$ addition 
was predicted to lead to $\mathrm{MgS}$ while Ce gave rise to precipitation of various Ce-bearing sulfides.

Mil'Man et al. [39] measured the surface tension and the contact angle at $1300^{\circ} \mathrm{C}$ of cast iron drops put on pseudo-single crystal graphite orientated with the basal or prism planes facing the melt. From this, they estimated the interfacial tension and the work of adhesion between graphite and liquid. The composition and density of every alloy were reported as well as the microstructure of the solidified drops. Table V lists the results for Mg-treated and Ce-treated alloys that gave nodular graphite, as well as for two untreated alloys (Flake I and Flake II) that gave lamellar graphite. Results for flake graphite alloys obtained by over-treating with $\mathrm{Ce}$ and by adding $\mathrm{Al}$ are also listed in Table $\mathrm{V}$. The authors also studied alloys that have been $\mathrm{Mg}$-treated and to which $\mathrm{Bi}, \mathrm{Sb}$ and $\mathrm{Sn}$ were added, either alone or with $\mathrm{Ce}$. The corresponding results are not reported here but the values of the work of adhesion are used in Fig. 9 of the main text. This work is the only one in which oxygen content was measured, varying from 7-8 ppm for the spheroidized melts to $18-35 \mathrm{ppm}$ for the untreated melts. Using this latter content for Flake II alloy, the oxygen activity was calculated at $3 \cdot 10^{-9}$ with associated precipitation of silicon oxides (tridymite and pyroxene).

Takita and Ueda [44] compared the interfacial energy of plate-like and spheroidal graphite, accounting for internal boundaries between sectors for this latter shape. For doing this comparison, they performed sessile drop experiments at $1180^{\circ} \mathrm{C}$ on various alloys. Three $\mathrm{Mg}$ bearing alloys were obtained by pouring a melt with initially $0.06 \mathrm{wt} . \% \mathrm{Mg}$ after various times of holding in the furnace so as to obtain three decreasing Mg levels. Two other alloys were added with $\mathrm{Pb}$, one in which was subsequently added $\mathrm{Mg}$ and the other not. The drops were put on a polycrystalline or pyrolytic graphite, this latter being assumed to be orientated with the basal planes facing the melt. Their results are listed in Table VI where it is seen here also that the surface tension slightly varies with the graphite orientation which is dubious. 
Table II. Composition (wt.\%), calculated sulfur activity, measurement temperature $\left({ }^{\circ} \mathrm{C}\right)$ and experimental surface tension $\left(\mathrm{mN} . \mathrm{m}^{-1}\right)$ of cast irons. Data from Kozakevitch et al. [15].

\begin{tabular}{|l|l|l|l|l|l|l|l|}
\hline$\% \mathrm{C}$ & $\% \mathrm{Si}$ & $\% \mathrm{Mn}$ & $\% \mathrm{P}$ & $\% \mathrm{~S}$ & as & Temperature & $\sigma$ experimental \\
\hline 3.32 & 2.76 & 0.56 & 0.490 & 0.120 & $4.05 \cdot 10^{-4}$ & 1318 & 914 \\
\hline 4.22 & 1.70 & 3.44 & 0.052 & 0.004 & $1.58 \cdot 10^{-5}$ & 1450 & 1167 \\
\hline 3.52 & 2.55 & 0.50 & 0.68 & 0.039 & $1.87 \cdot 10^{-4}$ & 1405 & 1083 \\
\hline 3.56 & 2.76 & 0.58 & 0.085 & 0.036 & $1.82 \cdot 10^{-4}$ & 1423 & 953 \\
\hline 3.66 & 2.50 & 0.25 & 0.13 & 0.019 & $9.96 \cdot 10^{-5}$ & 1420 & 1018 \\
\hline 3.74 & 2.22 & 0.24 & 0.13 & 0.124 & $4.69 \cdot 10^{-4}$ & 1325 & 871 \\
\hline 3.87 & 1.78 & 0.51 & 0.17 & 0.086 & $4.09 \cdot 10^{-4}$ & 1410 & 881 \\
\hline 4.00 & 1.07 & 0.18 & 0.065 & 0.042 & $1.61 \cdot 10^{-4}$ & 1342 & 915 \\
\hline 3.75 & 2.60 & 0.46 & 0.095 & 0.028 & $1.54 \cdot 10^{-4}$ & 1436 & 955 \\
\hline 4.1 & 1.88 & 0.54 & 0.085 & 0.040 & $1.93 \cdot 10^{-4}$ & 1397 & 926 \\
\hline 4.12 & 1.56 & 0.48 & 0.075 & 0.028 & $1.16 \cdot 10^{-4}$ & 1358 & 945 \\
\hline 4.18 & 0.66 & 0.45 & 0.085 & 0.016 & $4.48 \cdot 10^{-5}$ & 1290 & 1060 \\
\hline 3.87 & 0.94 & 0.40 & 0.070 & 0.008 & $2.30 \cdot 10^{-5}$ & 1290 & 1148 \\
\hline 3.44 & 2.56 & 0.22 & 0.11 & 0.006 & $8.6 \cdot 10^{-6}$ & 1410 & 1325 \\
\hline 3.8 & 2.18 & 0.51 & 0.14 & 0.002 & $1.08 \cdot 10^{-5}$ & 1440 & 1351 \\
\hline
\end{tabular}


Table III. Composition (wt.\%), calculated sulfur activity, experimental surface tension $\left(\mathrm{mN} . \mathrm{m}^{-1}\right)$, contact angle $\left(^{\circ}\right)$ and interface tension $\left(\mathrm{mN}^{\mathrm{m}} \mathrm{m}^{-1}\right)$. Data from McSwain et al. $[43,51]$ for trials at $1200^{\circ} \mathrm{C}$. Poly stands for polycrystalline.

\begin{tabular}{|l|l|l|l|l|l|l|l|l|l|}
\hline Alloy reference & $\% \mathrm{C}$ & $\% \mathrm{Si}$ & $\% \mathrm{Mn}$ & $\% \mathrm{~S}$ & other & as & $\begin{array}{l}\text { Surface tension } \\
\text { (basal/poly/prism) }\end{array}$ & Contact angle & $\begin{array}{l}\text { Interfacial tension } \\
\text { (basal/poly/prism) }\end{array}$ \\
\hline $\mathrm{S}$ alloy & 3.72 & 2.43 & 0.30 & 0.050 & -- & $1.15 \mathrm{e}-4$ & $1057 / 1017 / 1153$ & $106 / 85 / 77$ & $1270 / 951 / 846$ \\
\hline $\mathrm{Mg}$ alloy & 3.70 & 2.80 & 0.50 & 0.010 & $0.037 \% \mathrm{Mg}$ & $8.8 \cdot 10^{-8}$ & $1128 / 1167 / 1147$ & $115 / 117 / 123$ & $1460 / 1621 / 1721$ \\
\hline $\mathrm{Ce}$ alloy & 3.35 & 2.35 & 0.30 & 0.005 & $0.10 \mathrm{Ce}$ & $1.2 \cdot 10^{-9}$ & $1335 / 1463 / 1311$ & $105 / 109 / 112$ & $1323 / 1504 / 1579$ \\
\hline $\mathrm{Bi}$ alloy & 3.72 & 2.43 & 0.30 & 0.005 & $0.005 \mathrm{Bi}$ & & $1342 /--/ 1331$ & $98 /--/ 98$ & $1172 /--/ 1277$ \\
\hline $\mathrm{Sb}$ alloy & 3.72 & 2.43 & 0.30 & 0.005 & $0.059 \mathrm{Sb}$ & & $1280 /--/ 1253$ & $104 /--/ 90$ & $1293 /--/ 1085$ \\
\hline
\end{tabular}

Table IV. Composition (wt.\%), calculated sulfur activity, measurement temperature $\left({ }^{\circ} \mathrm{C}\right)$, experimental surface tension $\left(\mathrm{mN}^{\circ} \mathrm{m}^{-1}\right)$ and contact angle $\left({ }^{\circ}\right)$. Data from Selçuk and Kirkwood [37].

\begin{tabular}{|c|c|c|c|c|c|c|c|c|c|c|}
\hline Alloy reference & $\% \mathrm{C}$ & $\% \mathrm{Si}$ & $\% \mathrm{Mn}$ & $\% \mathrm{P}$ & $\% \mathrm{~S}$ & Other & $a_{s}$ & Temperature & Surface tension & Contact angle \\
\hline 1 initial & 3.58 & 2.6 & 0.14 & 0.022 & 0.012 & 0.038 wt. $\% \mathrm{Mg}$ & $5.3 \cdot 10^{-8}$ & 1180 & $1380 / 1490$ & 140 \\
\hline 160 ' holding & & & & & & 0.008 wt. $\% \mathrm{Mg}$ & $4.0 \cdot 10^{-6}$ & 1180 & $1150 / 1190$ & 128 \\
\hline 2 initial & 3.68 & 2.58 & 0.13 & 0.026 & 0.020 & 0.08 wt. $\% \mathrm{Ce}$ & $3.7 \cdot 10^{-8}$ & 1200 & $1480 / 1590$ & 144 \\
\hline $260^{\prime}$ holding & & & & & & 0.03 wt. $\% \mathrm{Ce}$ & $2.4 \cdot 10^{-5}$ & 1200 & 1010 & 136 \\
\hline 3 initial & 3.68 & 2.58 & 0.13 & 0.026 & 0.022 & -- & $5.39 \cdot 10^{-5}$ & 1200 & $950 / 1150$ & 130 \\
\hline 330 ' holding & & & & & 0.003 & & $7.36 \cdot 10^{-6}$ & 1200 & 1290 & 125 \\
\hline 4 initial & 3.72 & 2.51 & 0.13 & 0.028 & 0.020 & 0.095 wt. $\% \mathrm{Ce}$ & $2.4 \cdot 10^{-8}$ & 1215 & 1880 & \\
\hline
\end{tabular}


Table V. Composition (wt.\%), calculated sulfur activity, experimental surface tension $\left(\mathrm{mN} . \mathrm{m}^{-1}\right)$ and contact angle $\left(^{\circ}\right)$. Data from Mil'man et al. [39] at $\mathbf{1 3 0 0}^{\circ} \mathrm{C}$

\begin{tabular}{|l|l|l|l|l|l|l|l|l|l|l|}
\hline Alloy reference & $\% \mathrm{C}$ & $\% \mathrm{Si}$ & $\% \mathrm{Mn}$ & $\% \mathrm{P}$ & $\% \mathrm{~S}$ & $\mathrm{O} \mathrm{ppm}$ & Other addition & as & Surface tension & $\begin{array}{l}\text { Contact angle } \\
\text { Basal/prism }\end{array}$ \\
\hline Mg-treated & 3.52 & 2.89 & 0.33 & 0.001 & 0.004 & 7 & $0.09 \% \mathrm{Mg}$ & $3.5 \cdot 10^{-7}$ & 1622 & $140 / 149$ \\
\hline Ce-treated & 3.51 & 2.85 & 0.33 & 0.001 & 0.004 & 8 & $0.18 \% \mathrm{Ce}$ & $8.6 \cdot 10^{-9}$ & 1590 & $141 / 148$ \\
\hline Flake-I & 3.53 & 2.89 & 0.31 & 0.028 & 0.019 & 35 & & $6.6 \cdot 10^{-5}$ & 1034 & $101 / 94$ \\
\hline Flake-II & 3.58 & 2.79 & 0.30 & 0.001 & 0.004 & 18 & & $1.4 \cdot 10^{-5}$ & 1380 & $121 / 113$ \\
\hline Flake+Ce & 3.52 & 2.9 & 0.30 & 0.001 & 0.003 & 16 & $0.7 \% \mathrm{Ce}$ & & 1110 & $141 / 144$ \\
\hline Flake-II+Al & & & & & & & $0.16 \% \mathrm{Al}$ & & 1590 & $111 / 107$ \\
\hline
\end{tabular}

Table VI. Composition (wt.\%), calculated sulfur activity, experimental surface tension $\left(\mathrm{mN} . \mathrm{m}^{-1}\right)$ and contact angle $\left({ }^{\circ}\right)$. Data from Takita and Ueda [44] for trials at $1180^{\circ} \mathrm{C}$. "Pyro" stands for pyrolytic.

\begin{tabular}{|l|l|l|l|l|l|l|l|l|l|}
\hline Alloy reference & $\% \mathrm{C}$ & $\% \mathrm{Si}$ & $\% \mathrm{Mn}$ & $\% \mathrm{P}$ & $\% \mathrm{~S}$ & Other addition & as & $\begin{array}{l}\text { Surface tension } \\
\text { Pyro/polycrystal }\end{array}$ & $\begin{array}{l}\text { Contact angle } \\
\text { Pyro/polycrystal }\end{array}$ \\
\hline $0.06 \mathrm{Mg}$ & 3.52 & 2.66 & 0.01 & 0.008 & 0.004 & $0.052 \% \mathrm{Mg}$ & $3.1 \cdot 10^{-8}$ & $1390 / 1270$ & $102 / 126$ \\
\hline $0.04 \mathrm{Mg}$ & 3.64 & 2.75 & 0.01 & 0.009 & 0.016 & $0.039 \% \mathrm{Mg}$ & $5.7 \cdot 10^{-8}$ & $1220 / 1110$ & $112 / 136$ \\
\hline $0.02 \mathrm{Mg}$ & 3.69 & 2.70 & 0.00 & 0.009 & 0.009 & $0.015 \% \mathrm{Mg}$ & $1.8 \cdot 10^{-7}$ & $1320 / 1330$ & $123 / 141$ \\
\hline $\mathrm{Pb}-\mathrm{Mg}$ & 3.40 & 2.39 & 0.01 & 0.003 & 0.003 & $0.069 \% \mathrm{Mg}, 0.032 \% \mathrm{~Pb}$ & & $1230 / 1260$ & $103 / 112$ \\
\hline $\mathrm{Pb}$ & 3.58 & 2.49 & 0.00 & 0.009 & 0.009 & $0.005 \% \mathrm{Mg}, 0.149 \% \mathrm{~Pb}$ & & $1400 / 1350$ & $108 / 101$ \\
\hline
\end{tabular}


